\title{
AVALIAÇÃO DA ADAPTAÇÃO DA INTERFACE INTERMEDIÁRIOS/CILINDROS DE PLÁSTICO FUNDIDOS EM TITÂNIO E COBALTO-CROMO, ANTES E APÓS SOLDAGEM A LASER
}

\section{DANIELA CASTILIO}

Dissertação apresentada `a Faculdade de Odontologia de Bauru da Universidade de São Paulo, como parte dos requisitos para obtenção do título de Mestre em Reabilitação Oral.

(Edição revisada)

Orientador:

Wellington Cardoso Bonachela

Co-orientador: César Antunes de Freitas

BAURU

2000 


\section{Castilio, Daniela}

C278a Avaliação da adaptação da interface intermediários/cilindros de plástico fundidos em titânio e cobalto-cromo, antes e após soldagem a laser / Daniela Castilio

Bauru, 2000.

103p.: il.; $30 \mathrm{~cm}$.

Tese (Mestrado) -- Faculdade de Odontologia de Bauru, Universidade de São Paulo

Orientador: Prof. Dr. Wellington Cardoso Bonachela

Autorizo, exclusivamente para fins acadêmicos e científicos, a reprodução total ou parcial desta dissertação/tese, por processos fotocopiadores e/ou meios eletrônicos

Assinatura do autor:

Data: 


\section{DANIELA CASTILIO}

21 de julho de 1973

Bauru - SP

Filiação

1991-1995

1996-1998

1996-1998

1996

$1998-2000$
Nascimento

Celso Castilio

Sueli Aparecida Castilho Castilio

Curso de Graduação em Odontologia na Universidade do Sagrado Coração - Bauru - SP.

Curso de especialização em Prótese Dental, promovido pela PROFIS.

Residência Odontológica na Área de Prótese Dental no Hospital de Pesquisa e Reabilitação de Lesões Lábio-Palatais, da Universidade de São Paulo, promovido pela PROFIS.

Professor de Departamento de Odontologia da Universidade do Sagrado Coração.

Curso de Pós-Graduação em reabilitação Oral, em nivel de Mestrado, na Faculdade de Odontologia de Bauru. 


\section{A DEUS}

"Que nos deu o Dom da vida, nos presenteou com a liberdade, nos abençoou com a inteligência, nos deu a graça de lutarmos para a conquista de nossas realizações. A Ele cabe o louvor e a glória, cabe a nós, somente agradecê-lo." 


\title{
DEDICO ESTE TRABALHO,
}

\begin{abstract}
Aos meus pais, Celso e Sueli, com seus constante incentivo e suas admiráveis experiências de vida, jamais permitiram render-me perante os desafios ou me deixar vencer pelas dificuldades; com seu apoio e carinho sempre me ajudaram a substituir o medo e o desânimo pela esperança e a motivação; com seus exemplos de vida e de conduta, transmitiram-me o mais valioso dos ensinamentos: a melhor maneira de prosseguir na caminhada é viver com dignidade; foram os responsáveis pela minha formação humana e profissional.
\end{abstract}


Ao meu namorado, companheiro e amigo, José Henrique, por ter me compreendido e apoiado nos momentos difíceis; me dedicado carinho e amor em todos os momentos. O seu apoio em minhas decisões, a sua confiança na minha capacidade, os seus conselhos sinceros e a sua motivação foram essenciais para a concretização desta minha realização profissional e pessoal. 


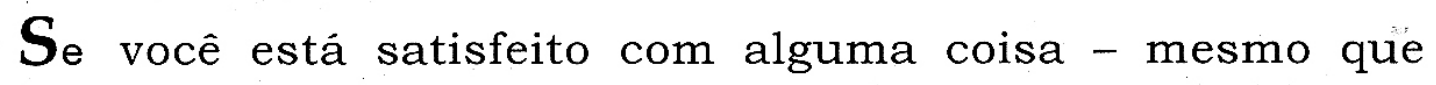
seja uma coisa boa, que gostaria de realizar e não está conseguindo - páre agora.

Se as coisas não andam, só existem duas explicações: ou sua perseverança está sendo testada ou você precisa mudar de rumo.

Para descobrir qual das opções é correta - já que são atitudes opostas - use o silêncio e a oração. Aos poucos as coisas vão ficando misteriosamente claras, até você ter forças suficientes para escolher.

Uma vez tomada a decisão, esqueça por completo a outra possibilidade. E siga adiante, porque Deus é o Deus dos Valentes.

\section{Disse Domingos Sabino:}

"Tudo sempre acaba bem no final. Se as coisas não estão bem, é porque você ainda não chegou ao final.” 


\section{AGRADECIMENTOS ESPECIAIS}

Ao Prof. Dr. Wellington Cardoso Bonachela, além de orientador, tem sido um amigo, exemplo de dedicação à profissão e alicerce no qual me apoiei. Meus sinceros agradecimentos por ter sido aquele que mesmo sabendo das minhas limitações, acreditou na minha vontade e dedicação, fazendo com que minha vida tomasse um novo rumo.

Ao Prof. Dr. César Antunes de Freitas, exemplo extremo de dedicação, conhecimento, competência e amizade, meu profundo e sincero agradecimento.

Às minhas amigas, Andrea e Letícia, pelo apoio, incentivo e presença marcante em minha vida. Pela amizade enriquecedora e inesquecivel neste período em que permaneceram em Bauru.

À Universidade do Sagrado Coração, em especial a Ir. Marisabel Leite, pelo grande incentivo e contribuição para a realização do curso de pós-graduação. 


\section{AGRADECIMENTOS}

À Faculdade de Odontologia de Bauru, da Universidade de São Paulo, representada pelo Diretor Professor Doutor Aymar Passanezi.

Ao Prof. Dr. Luiz Fernando Pegoraro, atual Presidente da Pós-Graduação e Professor do Curso de Pós-Graduação em Reabilitação Oral, pelos conhecimentos transmitidos neste período de convivência.

Ao Prof. Dr. Gerson Bonfante, pela confiança e incentivo durante toda minha vida profissional.

Aos Professores Doutores do Departamento de Prótese, da Faculdade de Odontologia de Bauru - USP, Accácio Lins do Valle, Carlos do Reis Pereira de Araújo, Gerson Bonfante, José Henrique Rubo, José Valdes Conti, Lucimar Falavinha Vieira, Luiz Fernando Pegoraro, Milton Carlos Gonçalves Salvador, Paulo César Rodrigues Conti, Paulo Martins Ferreira, Renato de Freitas, Valércio Bonachela, Wellington Cardoso Bonachela. 
Aos colegas de Mestrado, Andreia, Anuar, Carlos, Juliano, Letícia, Mário, Murilo, Nelson, Sérgio, Vinícius Porto, Vinícius Janson, Wagner e William, que dividiram comigo, tanto a vontade de progredir na Odontologia como os desafios enfrentados para alcançar este objetivo.

Aos colegas do Doutorado: Daniel, Henrique, Hidechi, João, Luciano, Luiz, Matterson e Sérgio, sempre dispostos a colaborar.

$\boldsymbol{A}$ todos os professores do Departamento de Prótese da Universidade do Sagrado Coração: Ana Aída, Eduardo, Fátima, Gerson, Gilmar, Ivete, João, José Fernando, Juliana, Pedro, Regina, Rubens, Sérgio, Simone e Walter, pelo companheirismo e compreensão da minha ausência, necessária para conclusão de mais esta etapa.
$\grave{A}$ empresa Conexão, pela cessão dos materiais utilizados neste trabalho.

Ao Laboratório Vaiazi, em especial ao Rômulo, Toninho e Gerson, pela valiosa ajuda prestada nas etapas laboratoriais deste trabalho. 
Aos funcionários do Departamento de Prótese, pelo auxílio prestado e pelo carinho dedicado em diversos momentos.

$\boldsymbol{A}$ todos os funcionários da Pós-Graduação, pelo carinho e atenção que sempre demonstraram ter por nós, pósgraduandos.

Ao Departamento de Materiais Dentários e a seus professores sempre prestativos.

Ao Prof. Dr. José Roberto Lauris, pela sua eficiência na elaboração e sugestões na análise estatística.

Aos funcionários da Biblioteca, pela cordialidade e atenção a mim dispensadas.

Ao Salvador, funcionário da Associação de Pós-Graduação, pela importância do trabalho que prestam a nós, pósgraduandos.

Aos alunos e pacientes meu afeto e minha sincera gratidão. 
Ao meu amigo Marcelo, agradeço pelo apoio e incentivo.

$\boldsymbol{E}$ a todos os meus amigos e amigas aqui não citados, mas também responsáveis por esta conquista.

"Se não houver frutos

Valeu a Beleza das flores

Se não houver flores

Valeu a sombra das folhas

Se não houver folhas

Valeu a intenção da semente."

Henfil 


\section{Lista de Figuras}

Pág.

Figura 4.1 - Modelo mestre e o posicionamento dos implantes. 44

Figura 4.2 - Cilindro de plástico demarcado para padronização do 45 enceramento.

Figura 4.3 - Cilindros de plástico encerados. 45

Figura 4.4 - Corpo de prova encerado. 46

Figura 4.5 - Corpos de prova posicionados na barra de cera. 48

Figura 4.6 - Estruturas metálicas obtidas em liga de Co-Cr. 49

Figura 4.7 - Vista superior do anel metálico para fundição do titânio. $\quad 51$

Figura 4.8 - Aparelho para fundição de titânio - rematitan ${ }^{\circledR}$.

Figura 4.9 - Lingotes de titânio. 53

Figura 4.10 - Visão interna do aparelho de fundição de titânio - 53 rematitan ${ }^{\circledR}$.

Figura 4.11 - Microscópio óptico comparador utilizado. 56

Figura 4.12 - Modelo mestre posicionado para leitura - visão frontal. 56

Figura 4.13 - Estrutura metálica seccionada. $\quad 58$

Figura 4.14 - Aparelho de solda a laser. $\quad 58$

Figura 4.16 - Estrutura metálica após soldagem. 59

Figura 5.1 - Gráfico das médias das variáveis estudadas, ou seja, 65 Cilindros $(1,2,3)$, Técnicas( monobloco, soldagem) e Materiais ( $\mathrm{Ti}, \mathrm{Co}-\mathrm{Cr}$ ). 
Figura 5.2 - Análise de variância a três critérios de classificação 66 aplicada aos resultados dos diferentes grupos.

Figura 5.3 - Média geral das ligas e técnicas estudadas. $\quad 67$

Figura 6.1 - Valores médios da interface componente 70 protético/intermediário $(\mu \mathrm{m})$ fundidos em monobloco e após a soldagem.

Figura 6.2 - Valores médios da interface componente 70 protético/intermediário $(\mu \mathrm{m})$ fundidos em titânio e cobaltocromo. 


\section{Lista de Tabelas}

Pág.

Tabela 1 - Valores médios da interface componente 61 protético/intermediário $(\mu \mathrm{m})$, obtidos a partir da fundição em monobloco de cilindros usinados em plástico, com liga de titânio.

Tabela 2 - Valores médios da interface componente 62 protético/intermediário $(\mu \mathrm{m})$, obtidos a partir da fundição em monobloco de cilindros usinados em plástico, com liga de cobalto-cromo.

Tabela 3 - Valores médios da interface componente 63 protético/intermediário $(\mu \mathrm{m})$, obtidos a partir da soldagem a laser de cilindros usinados em plástico, fundidos com liga de titânio.

Tabela 4 - Valores médios da interface componente protético/intermediário $(\mu \mathrm{m})$, obtidos a partir da soldagem a laser de cilindros usinados em plástico, fundidos com liga de cobalto-cromo.

Tabela 5 - Valores médios e desvios padrões da interface componente 64 protético/intermediário $(\mu \mathrm{m})$, fundidos em liga de titânio e cobalto-cromo, antes e após soldagem 


\section{Lista de Abreviaturas e Símbolos}

\begin{tabular}{|c|c|}
\hline ADA & American Dental Association \\
\hline $\mathrm{Al}$ & Alumínio \\
\hline $\mathrm{Be}$ & Berílio \\
\hline${ }^{\circ} \mathrm{C}$ & grau Celsius \\
\hline $\mathrm{cm}$ & centímetros \\
\hline $\mathrm{cm}^{2}$ & centímetro quadrado \\
\hline $\mathrm{CO}_{2}$ & dióxido de carbono \\
\hline $\mathrm{Co}-\mathrm{Cr}$ & Cobalto-Cromo \\
\hline Co & Cobalto \\
\hline $\mathrm{Cr}$ & Cromo \\
\hline${ }^{\circ} \mathrm{F}$ & grau Farenheit \\
\hline gr & gramas \\
\hline $\mathrm{Hz}$ & Hertz \\
\hline KV & Kilovoltagem \\
\hline $\mathrm{L} / \mathrm{min}$ & litros por minuto \\
\hline $\mathrm{Lb} / \mathrm{pol}^{2}$ & libra força por polegada ao quadrado \\
\hline MA & Miliamperagem \\
\hline mcal & milicalorias \\
\hline $\mathrm{ml}$ & mililitros \\
\hline $\mathrm{mm}$ & milímetros \\
\hline Mo & Molibdênio \\
\hline $\mathrm{MPa}$ & MegaPascal \\
\hline $\mathrm{m} / \mathrm{seg}$ & metros por segundo \\
\hline
\end{tabular}


ms

N

$\mathrm{Ncm}$

$\mathrm{Nd}: Y A G$

$\mathrm{Ni}$

$\mathrm{Ni}-\mathrm{Cr}$

N.Y.

Pd-Ag

PPF

PTVs

seg

RPM

Ti

USA

UTS

V

W

Y

YS

$\mu \mathrm{m}$ milisegundos

Newton

Newtons centímetros

Neodínio-Ítrio-Alumínio-Granada

Níquel

Níquel-Cromo

New York

Paládio-Prata

prótese parcial fixa

valores do Periotest

segundos

rotações por minuto

Titânio

United States of America

resistência à tensão

Volts

Watts

Ítrio

resistência do produto

micrometro 
RESUMO 


\section{RESUMO}

A condição passiva da adaptação das próteses implanto-suportadas é um requisito básico para o sucesso do tratamento.

O objetivo deste estudo foi avaliar a adaptação da interface intermediário/componentes protéticos (cilindros), fundidos, em titânio e cobalto-cromo, em monobloco e após a realização da soldagem a laser.

Foram utilizados 30 cilindros torneados em plástico e 15 barras cilíndricas para a interligação dos componentes protéticos (cilindros). Cada corpo de prova apresentava três componentes protéticos unidos entre si. Um total de 10 corpos de prova foram realizados, sendo que destes, 5 foram fundidos em titânio e os outros 5 fundidos em liga de cobalto-cromo.

As análises e mensurações das interfaces foram feitas antes e após a soldagem a laser, com a utilização de um microscópio comparador. Os resultados mostraram que as estruturas fundidas em monobloco (peça única) apresentaram uma maior interface (desajuste médio de $26,164 \mu \mathrm{m}$ ) que as mesmas após a soldagem a laser (desajuste médio de 19,943 $\mu \mathrm{m}$ ). Foram encontradas diferenças estatisticamente significantes também entre os dois materiais utilizados, sendo que o titânio (desajuste médio de $21,262 \mu \mathrm{m}$ ) apresentou melhores resultados que o cobalto-cromo (desajuste médio de $24,845 \mu \mathrm{m})$. 


\section{SUMARIO}

LISTA DE FIGURAS xii

LISTA DE TABELAS xiv

LISTA DE ABREVIATURAS E SIMBOLOS XV

RESUMO

1 - INTRODUÇÃO

2 - REVISÄO DE LITERATURA

3 - PROPOSIÇĀO 41

4 - MATERIAL E MÉTODOS 43

5 - RESULTADOS

6- DISCUSSÄO 69

$\begin{array}{ll}7 \text { - CONCLUSŌES } & 76\end{array}$

$\begin{array}{ll}\text { ANEXOS } & 78\end{array}$

REFERÊNCIAS BIBLIOGRÁFICAS

$\begin{array}{lr}\text { ABSTRACT } & 93\end{array}$ 
INTRODUÇ ÃO 


\section{INTRODUÇ $\tilde{A} O$}

Hoje, os reflexos das mudanças ocorridas na Odontologia, nos últimos 30 anos, são notáveis, principalmente na área reabilitadora. Os implantes osseointegrados assumiram um papel definitivo nestas, graças a sua condição de aceitação biológica por parte dos pacientes e sua alta previsibilidade de sucesso nos tratamentos dentais.

Os estudos iniciados por Per Ingvar Bränemark e colaboradores, nos finais dos anos 50, resultaram no esplendor em que vivemos. A possibilidade de devolver dentes a indivíduos edêntulos, de maneira organizada, rotineira e confiável nos fascina muito na atualidade.

É lógico pensar que, no sentido coerente da evolução das pesquisas, novas tecnologias vão se agregando às já existentes, permitindo alimentar cada vez mais nossos conhecimentos. Isto acontece hoje com as ligas de titânio, às quais extrapolam a sua condição de aceitação biológica perfeita, permitindo ao tecido ósseo que interaja com a mesma, determinando o fenômeno da osseointegração. $\mathrm{Na}$ atualidade, o titânio tem na bioengenharia um forte apelo como material restaurador protético devido às suas propriedades inerentes. $O$ titânio apresenta 5 características que 0 faz valioso para o uso odontológico: 1- Alta resistência mecânica; 2- Alta resistência à corrosão; 3- Biocompatibilidade; 4- Ação bacteriostática contra a flora bacteriana encontrada na boca; 5- Único metal que pode ser soldado na boca. Além destas características apresenta a vantagem de ser mais barato que as ligas áureas ${ }^{27}$.

O alto custo do ouro e outras ligas preciosas, tal como a espessura excessiva, necessária para manter rigidez abaixo da porcelana, tem levado muitos dentistas a utilizar ligas não preciosas ${ }^{2,18,44}$.

As ligas de cobalto-cromo têm sido utilizadas na Odontologia por mais de 60 anos como liga-padrão para a confecção de estruturas para próteses parciais removíveis, desde que foram introduzidas para uso odontológico na década de 30 por Erdle \& Prange. Estas ligas apresentam algumas vantagens em relação as 
ligas de ouro: (1) baixo peso específico (densidade); (2) boa resistência à corrosão e ao manchamento; (3) baixo custo, sendo o valor 10 vezes menor que as ligas de ouro; (4) alto módulo de elasticidade (rigidez), sendo 2 vezes mais alto que o ouro tipo IV e (5) alta dureza e temperatura de fusão. No entanto, apresentam algumas desvantagens: (1) exibem menor definição de detalhes; (2) maior dificuldade de acabamento e polimento; (3) maior contração durante a fundição aproximadamente duas vezes maior que o ouro tipo IV; (4) requer equipamento especial para este processo ${ }^{12,13,15,61,71,74}$.

Fundições de próteses fixas convencionais em monobloco são técnicas sensíveis que apresentam um certo grau de distorção, o qual torna-se inevitável, segundo SCHIEFFLEGER et al ${ }^{67}$ (aproximadamente $100 \mu \mathrm{m})$. As duas maiores preocupações com próteses fixas suportadas por implantes osseointegrados são (1) as dificuldades técnicas na obtenção de uma adaptação precisa entre a infra-estrutura metálica com o intermediário e componentes, quando os parafusos de ouro são apertados, e (2) o alto custo quando ligas de ouro são utilizadas para as infra-estruturas. A soldagem a laser das infra-estruturas de titânio tem sido sugerida como uma técnica para solucionar ambos os problemas ${ }^{35,68}$.

A soldagem a laser do titânio tem sido usada desde 1987 como uma alternativa para restaurar a dentição de pacientes edêntulos com prótese fixas suportadas por implantes osseointegrados ${ }^{35}$. O uso de materiais similares das infra-estruturas protéticas aos componentes de implante tem uma vantagem óbvia. Outra vantagem do titânio é que diferentes componentes protéticos pré-maquinados podem ser fabricados e então simplesmente selecionados e unidos no laboratório através da solda a laser.

O aumento da precisão associada a solda a laser pode ser explicada parcialmente pela redução nos passos requeridos para obter a prótese final. A maior vantagem da solda a laser é a maior previsibilidade na quantidade da distorção, causada pelo processo de soldagem ${ }^{28}$. 
Quando a adaptação clínica da infra-estrutura com o intermediário do implante não é obtida inicialmente, o seccionamento e a soldagem é uma estratégia comum para melhorar a adaptação da infra-estrutura com 0 intermediário do implante ${ }^{72,81}$.

Analisando a importância da interface que se estabelece entre o intermediário e a infra-estrutura protética, na transmissão de carga entre os componentes do sistema e ao osso que os circunda, manifestou-se um interesse no desenvolvimento de um projeto que avaliasse qual seria a técnica mais precisa, dentre as propostas; combinada a dois materiais diferentes para confecção das infra-estruturas de próteses implantosuportadas. 
REVISÃO DE LITERATURA 


\section{REVISÃO DE LITERATURA}

Em 1958, MARKLEY ${ }^{48}$ observou as variáveis relacionadas à cera no procedimento de fundição. A distorção que ocorre durante a remoção do padrão, o alto coeficiente de expansão térmica linear e a resistência que o padrão de cera oferece à expansão de presa e higroscópica do revestimento, foram apontados como fatores importantes no comprometimento da qualidade final da adaptação das restaurações fundidas. Fatores estes que, ainda hoje, comprometem também a tecnologia das próteses sobre implantes osseointegrados.

GORDON; SMITH ${ }^{21}$, em 1970, descreveram princípios básicos, experiências e as vantagens da soldagem a laser para as próteses fixas e a adaptação de próteses parciais removíveis de precisão. A primeira soldagem prática foi realizada em dezembro de 1968. A soldagem foi feita em próteses fixas de 4 elementos. Eventualmente, a sobreposição dos tiros do laser foi necessária para o metal fluir. 19 pacientes tinham sido tratados com restaurações usando este método. Estas envolviam 104 unidades fixas e 3 próteses parciais removíveis com encaixes de precisão. Todas as soldas a laser tinham um comprimento de pulso de $8 \mathrm{~m} / \mathrm{seg}$ e tinham um nível de energia que alterava de 11 a 16 Joules. A soldagem a laser das próteses fixas foi um sucesso e nenhuma união falhou sob condições normais de uso pelos pacientes. Uma grande ênfase foi dada ao fato da soldagem induzir uma menor distorção, quando comparada àquelas resultantes das transferências e soldagem convencional. Salientou-se ainda que a separação das superfícies de metal não deve ser maior que 0,001 polegadas para que haja uma penetração adequada pela solda a laser. Os autores concluíram que a soldagem a laser é um procedimento laboratorial prático no qual a economia de tempo é considerável. 
Ainda em 1970, GORDON; SMITH ${ }^{22}$, apresentaram o laser como sendo a solução testada clinicamente para o problema mais crítico encontrado na construção de prótese metalocerâmica - a contração durante o procedimento de soldagem. O propósito deste estudo foi traçar os procedimentos de sucesso da solda a laser nas próteses metalocerâmicas. Trinta e três próteses de ouro e porcelana foram soldadas com esta técnica. A soldagem das próteses foi realizada diretamente no modelo mestre com 9 Joules por pulso e cada pulso durou 8 milisegundos. A primeira diferença entre a preparação da união a laser e da solda convencional é que, para o laser, o metal de cada lado da união deve ter um contato plano para obter melhor união. Isto contrasta com a solda convencional, a qual deve ter um espaço estreito entre as unidades a serem soldadas. A fusão da solda a laser irá penetrar de 0,5 a $1 \mathrm{~mm}$, dependendo da energia empregada e do tipo de metal. De acordo com os autores a soldagem a laser é um procedimento prático e apresenta as vantagens de facilidade, rapidez e precisão.

No ano de 1977, HULLING; CLARK ${ }^{28}$, avaliaram a distorção relativa em próteses de 3 elementos unidas por solda a laser, convencional ou fundidas em monobloco. Quinze próteses foram realizadas e todas fundidas em ouro. As distorções foram medidas com um ponto marcado no modelo mestre e um ponto nas próteses antes e após a soldagem. No caso da fundição em monobloco as distorções foram medidas no padrão de cera e após a fundição. Todas as medidas após a soldagem foram geralmente maiores que as originais, produzindo medidas positivas. Os autores concluíram que os três procedimentos utilizados para se unir unidades individuais de próteses fixas sempre acarretam algum grau de distorção. As técnicas de soldagem a laser e de fundição em monobloco produzem, entretanto, uma distorção significativamente menor que a soldagem convencional. 
Em 1983, em um dos primeiros trabalhos de biomecânica das próteses sobre implantes, SKALAK ${ }^{69}$ comentou que o aspecto crítico do sucesso ou falha dos implantes é a maneira como os estresses mecânicos são transferidos dos implantes ao tecido ósseo. É essencial que tanto o tecido ósseo como os implantes sejam submetidos somente a forças aos quais estão aptos a receber. Uma conexão rígida da prótese parcial fixa com o implante osseointegrado resulta em uma estrutura única, na qual prótese, implantes e osso agem como uma unidade. Qualquer desalinhamento que haja da prótese fixa com os implantes, resultará em um estresse interno da prótese, implantes e osso. Enfatizou que muito embora esses estresses não possam ser detectados por análise visual, podem ocasionar falhas mesmo sem a presença de forças externas.

APOTHEKER; NISHIMURA; SEERATTAN ${ }^{2}$, em 1984, compararam infra-estruturas soldadas a laser com aquelas soldadas convencionalmente. As infra-estruturas foram confeccionadas com a liga Rexillium III ( $\mathrm{Rx}$ Jeneric, Wallingford. CT), sendo esta uma liga popular, não preciosa, composta de $74-78 \% \mathrm{Ni}, 12-15 \% \mathrm{Cr}, 4-6 \%$ Mo e $1,8 \% \mathrm{Be}$. A temperatura de fundição variou de 2250 a $2350^{\circ} \mathrm{F}$. Foram enceradas 7 infra-estruturas de 3 elementos e de acordo com as instruções do fabricante incluídas e fundidas. O seccionamento da infra-estrutura foi feito com um disco de carborundum dupla face e o espaço produzido foi de $0,79 \mathrm{~mm}$. 3 infra-estruturas foram soldadas a laser com $450 \mathrm{~W} \mathrm{Nd}$ :YAG (John Blutt, Laser Industries, Lawrence, MA). Para cada prótese o pulso padrão foi de 48 pulsos/segundo com uma duração de 0,0004 segundos/pulso. As outras 3 próteses foram soldadas com o maçarico gás/oxigênio. As próteses foram colocadas no forno a uma temperatura de $1050^{\circ} \mathrm{F}$. Após 20 minutos foram removidas e a solda NNP (Rx Jeneric, Wallington, CT) aplicada. Todas as próteses soldadas pelo método convencional apresentavam porosidades amplas e profundas, já as soldadas a laser não apresentaram porosidades. Distintamente, uniões 
melhores e mais resistentes à fratura na boca foram encontradas com os corpos soldados a laser.

SCHIFFLEGER ${ }^{67}$ et al, em 1985, compararam próteses parciais fixas de 3, 4, 5 elementos fundidas em monobloco com uma liga de ouro para metalocerâmica. Foi utilizado uma matriz de alumínio composto por 3 peças que acomodava 5 preparos em aço puro para coroa total de canino a segundo molar. De um total de 18 fundições, foram feitas 6 fundições para cada um dos três tipos de prótese fixa. Para registrar as medidas de discrepância vertical marginal foi utilizado um microscópio com calibração micrométrica. As diferenças nas distâncias dos ângulos axio-gengivais entre a matriz e as fundições também foram registradas. As fundições foram então seccionadas, assentadas sobre a matriz e reposicionadas com resina Duralay, sendo que as medidas foram realizadas antes e após o seccionamento das peças. Os autores concluíram:

(1) $\mathrm{O}$ assentamento das fundições melhorou aproximadamente $50 \%$ após o seccionamento, o qual indica que as fundições estavam distorcidas.

(2) A distorção foi um fenômeno tridimensional, com a maior discrepância na superfície mesiogengival do retentor anterior e distolingual do retentor posterior;

(3) A distorção foi menor nas próteses fixas de 3 unidades e maior nas próteses fixas de 5 unidades;

(4) O diâmetro vestíbulo-lingual das fundições no ângulo gengivo-axial foi significantemente maior que os preparos do modelo mestre na maioria dos casos;

(5) O diâmetro mesio-distal das fundições no ângulo gengivoaxial foi menor que nos preparos do modelo mestre, mas foi somente significante nas próteses fixas de 3 unidades; 
(6) As fundições estavam ligeiramente sobrecontornadas ou subcontornadas, a razão principal das fundições não assentarem foi 0 empenamento.

HRUSKA ${ }^{27}$, em 1987, descreveu o uso do titânio na construção de coroas, próteses fixas e também técnicas de soldagem intra-oral destas próteses. A máquina usada nesta técnica consistia em um aparelho de soldagem eletrônica que realiza uma solda dentro da cavidade oral, sendo uma técnica segura e reproduzível. Devido a baixa condutibilidade térmica do titânio, não há transmissão de calor lateral do metal durante a união. A temperatura na área de solda é acima de $1600^{\circ} \mathrm{C}$ e mesmo assim não há risco de choque elétrico para o paciente. $O$ autor alertou que esta técnica só pode ser usada com titânio puro ou com ligas que contenham alta porcentagem de titânio.

CHAO et al ${ }^{11}$, em 1988, avaliaram a praticidade no uso das ligas de cobalto-cromo para fabricação de infra-estruturas de próteses sobre implantes e compararam os resultados com os obtidos nas infra-estruturas de paládio-prata. Os autores avaliaram a adaptação e o comportamento mecânico das infra-estruturas. Para a fabricação das infra-estruturas de cobalto-cromo foi necessária a duplicação dos cilindros de ouro em resina acrílica, pois a liga de cobalto-cromo não pode ser fundida sobre a liga de ouro. As infra-estruturas de paládio-prata foram realizadas sobre os cilindros de ouro. A adaptação marginal entre os cilindros dos padrões de acrílico e os análogos intermediários foi medida utilizando-se um microscópio óptico de magnificação 100 vezes. Foram realizadas 4 medidas em cada intermediário. Para compensar a contração da resina Duralay empregada para a confecção dos cilindros protéticos, uma fina camada de cera foi utilizada para readaptar as margens destes, sendo novamente mensurada a adaptação marginal. Os padrões foram então incluídos e fundidos. Uma outra medição das infra-estruturas fabricadas 
com a liga de cobalto-cromo foi realizada após o acabamento. As medidas nas infra-estruturas de paládio-prata foram realizadas somente após a fundição e acabamento. Para verificar o comportamento mecânico das infra-estruturas ao receberem carga, foram utilizados :"strain gauge" e análise fotoelástica. A maioria das infra-estruturas de cobalto-cromo receberam algum tipo de ajuste antes de se adaptarem passivamente aos intermediários. Todas as infra-estruturas de paládio-prata adaptaram-se passivamente sem qualquer ajuste. A média de abertura marginal nas infra-estruturas de cobalto-cromo foi de 26,4 $\mu \mathrm{m}$ e nas infra-estruturas de paládio-prata foi de $8 \mu \mathrm{m}$. Então, com relação à adaptação, as infraestruturas de cobalto-cromo são inferiores às de paládio-prata. Para os autores, estes resultados podem ter ocorrido devido à maior contração de fundição do cobalto-cromo e ao menor grau de adaptação dos cilindros de resina acrílica com relação aos cilindros de ouro. Para a substituição dos cilindros acrílicos duplicados, a utilização de cilindros de plástico préfabricados seria uma tentativa para solucionar este problema. Os autores concluíram que é possível construir infra-estruturas sobre implantes com a liga de cobalto-cromo utilizando um menor volume de material, sem diminuir sua capacidade de receber cargas. As fundições em monobloco das infra-estruturas de cobalto-cromo mostraram uma adaptação aceitável, mas foram claramente inferior às infra-estruturas de paládio-prata fundidas diretamente sobre os cilindros de ouro.

Neste mesmo ano, KAUFMAN ${ }^{46}$ mostrou, em seu trabalho, a possibilidade de várias aplicações clínicas do laser em Odontologia. $O$ termo laser pode ser definido como a "amplificação da luz pela emissão de radiação estimulada". O laser produz um raio luminoso intenso e coeso. Um tipo de laser é definido como o comprimento de onda da radiação que emite. Para propósitos dentais, os comprimentos das ondas de laser variam de ultravioleta a infravermelho, dependendo do efeito desejado. A maioria dos lasers permitem que o operador varie a energia, o tempo de exposição e, em alguns casos, o comprimento de onda e o diâmetro do 
raio luminoso. Ondas contínuas de laser emitem níveis constantes de energia por um período de escolha $(0,1 ; 0,5 ; 1 ; 2 ; 10$ segundos ou mais). Alguns lasers provêm pequenos pulsos de energia, fornecendo um número de pulsos por segundo $(20 \mathrm{~Hz}$ igual 20 pulsos/segundo) por um período escolhido. Uma grande variedade de lasers têm sido usados em experimentos dentais, os mais comumente são: 1- laser de dióxido de carbono $\left(\mathrm{CO}_{2}\right)$ com comprimento de onda aproximadamente de 9,32 a 10,59 $\mu \mathrm{m}$; 2- laser de neodínio-ítrio-alumínio-granada ( $\mathrm{Nd:YAG)} \mathrm{com}$ comprimento de onda $1,06 \mu \mathrm{m}$.

SJÖGREN; ANDERSSON; BERGMAN ${ }^{68}$ (1988) avaliaram a resistência a tensão, estresse e a elongação das uniões de titânio fundidas a laser considerando a praticabilidade de seu uso nas prótese dentais. $O$ laser Nd:YAG foi utilizado para realização destas soldagens. Durante os testes de tensão todas as amostras soldadas a laser fraturaram no centro da união soldada. O grau de deformação na região da fratura foi maior para as amostras não soldadas a laser do que para as soldadas a laser.

De acordo com o COUNCIL ON DENTAL MATERIALS, INSTRUMENTS, AND EQUIPMENT ${ }^{14}$, em 1989, a razão da restrição do uso prévio dos metais não nobres foi a crença generalizada que as ligas, com menos de $75 \%$ ou $78 \%$ de conteúdo nobre, sofreriam manchamento ou corrosão na boca. Esta correlação foi refutada. O custo mais baixo das ligas alternativas tem sido exigido pelos dentistas e tem sido proporcionado com os avanços na metalurgia e o maior conhecimento destes materiais. Desde a especificação original número 5 da $A D A$, uma proliferação considerável de ligas e sistemas têm provado serem substitutos viáveis das ligas com alto conteúdo de ouro.

Após a otimização dos parâmetros para o processamento a laser, DOBBERSTEIN et al $^{17}$, em 1990, avaliaram a efetividade da soldagem a 
laser das ligas Gisadent KCM 83 (Co-Cr), Gisadent NCA e NCS-1 (Ni-Cr) e Sipal 306 (Pd-Ag) e suas combinações, com relação aos procedimentos convencionais para soldagem. A fusão das ligas foi realizada com laser $\mathrm{Nd}$ :YAG. Sob parâmetros de otimização do laser, os corpos de prova $(5 \mathrm{x}$ $20 \times 0,8 \mathrm{~mm}$ ) foram fundidos e os que se apresentavam soldados serviram como controle. Os valores de resistência ao dobramento e fratura foram obtidos na máquina de Ensaios Universal "Zwick 1445" a uma velocidade de $1 \mathrm{~mm} / \mathrm{min}$. Após testes preliminares, chegou-se à conclusão que deveria ser utilizado o teste dos 3 pontos, com uma distância de $10 \mathrm{~mm}$ entre os pontos de apoio. A resistência à fratura encontrada para os corpos de prova soldados pelo laser foi superior ao controle. As soldas a laser da liga Gisadent NCS-1 eram melhores do que as soldas da liga Gisadent NCA. Estes valores correspondem a resistência a fratura do material inicial da liga Gisadent NCS-1, porque nenhum corpo de prova se fraturou na área de solda. A avaliação da resistência à fratura das áreas de soldas para todas as ligas e suas combinações confirma a superioridade do procedimento de solda a laser com relação à solda convencional, sendo que as ligas Gisadent KCM 83 e NCS-1 atingiram os valores mais altos. Pode ser confirmada ainda a eficácia da soldagem de ligas com diferentes pontos de fusão. Os autores enfatizaram que pesquisas posteriores deveriam ser realizadas para avaliar as características químicas e biológicas das soldas a laser. A capacidade de reprodução, economia de tempo e a possibilidade de acabamento microscópico decorrente da pequena zona de fusão, são algumas vantagens que podem contribuir para o desenvolvimento da técnica de soldagem a laser.

ZARB; SCHMITT ${ }^{81}$, em 1990, descreveram os aspectos clínicos e complicações encontradas em 46 pacientes com próteses implantosuportadas, por um período de 4 a 9 anos. Problemas e complicações foram observadas e registradas em todas as etapas do tratamento. Os resultados mostraram que as principais complicações foram: falha na osseointegração em 21 implantes; fratura de 53 parafusos de ouro; fratura 
de 13 infra-estruturas de paládio-prata e desconforto muscular ou desordem da articulação têmporo-mandibular em 12 pacientes. A maioria dos problemas foram de natureza iatrogênica, mas alguns podem ser inerentes ao próprio método.

HULTERSTRÖM; NILSSON ${ }^{29}$, em 1991, desenvolveram uma técnica para o uso da liga de Co-Cr nas infra-estruturas das próteses fixas implanto-suportadas e avaliaram os pacientes tratados com esta técnica. Participaram deste estudo 63 pacientes que receberam um total de 67 próteses fixas com infra-estruturas fabricadas com a liga de cobalto-cromo. As conexões entre as infra-estruturas metálicas e os cilindros de ouro foram realizadas utilizando diferentes técnicas. As próteses foram examinadas por um período de 6 meses a 3 anos. Nenhuma complicação relacionada com o material utilizado foi constatada. A perda óssea excedendo $1,5 \mathrm{~mm}$ foi registrada em 1 ou mais implantes em 7 pacientes

JEMT ${ }^{34}$, em 1991, em um acompanhamento de 1 ano de 380 próteses totais fixas sobre implantes, obteve uma taxa de sucesso de $99,5 \%$ do tratamento protético. Embora as complicações tenham sido poucas, estas foram mais freqüentes na maxila. Entre as complicações encontradas destacaram-se: problemas de dicção $(31,2 \%)$, mordida do lábio e bochecha $(6,6 \%)$, irritação causada pelo cantilever $(3,1 \%)$, problemas gengivais (fístula, hiperplasia, inflamação - 1,7\%), fratura da estrutura metálica $(0,8 \%)$. Não houve fratura de nenhum dos componentes. Em relação ao afrouxamento dos parafusos de ouro, o autor relatou que 271 próteses $(69,3 \%)$ apresentaram os parafusos estáveis no primeiro controle (após 2 semanas), sendo que quase todos os parafusos reapertados nesse primeiro controle se apresentaram estáveis no controle seguinte (113 próteses). Apenas 7 próteses precisaram de mais de um reaperto para que os parafusos se estabilizassem. A instabilidade dos parafusos de ouro foi maior na maxila, sendo esta diferença 
estatisticamente significante. Quando 0 desenho da prótese está adequado, sendo esta rígida e apresentando uma adaptação passiva, o risco de fratura dos componentes é baixo e sua ocorrência é maior no primeiro ano de função e foi sugerido um protocolo para análise da adaptação da prótese. Considerando-se uma prótese fixa suportada por 5 implantes, numerados de 1 a 5 da direita para esquerda, a prótese deve ser posicionada e o parafuso 1 apertado totalmente. Por meio deste procedimento verifica-se a adaptação dos demais componentes. O procedimento deve ser repetido com o outro parafuso distal (parafuso 5). Uma vez verificada a adaptação, parte-se para o aperto de todos os parafusos, um de cada vez, iniciando-se pelo parafuso 2, depois 0 parafuso 4, depois o mais intermediário e eventualmente os dois parafusos distais. Cada parafuso deve ser apertado até sua primeira resistência, anotando-se a posição da chave e um máximo de $1 / 2$ volta $\left(180^{\circ}\right)$ deve ser dado na chave para o aperto final. Outra forma utilizada para avaliar a adaptação foi pela quantidade de voltas dadas durante o aperto do parafuso de ouro. Quando mais de meia volta era necessária para apertar completamente o parafuso, a prótese era considerada mal adaptada, sendo separada e soldada.

Para GOLL ${ }^{20}$ (1991) há uma grande dificuldade em se obter uma infra-estrutura com adaptação, já que todo passo da confecção de uma prótese implanto-suportada é crítico. O autor sugeriu algumas soluções para melhorar a precisão das próteses, assim como reduzir alguns erros:

1. usar componentes usinados, pois sua adaptação é mais previsível;

2. checar a adaptação do cilindro de ouro e componentes de transferência nos intermediários na primeira consulta, para assegurar-se que todos os componentes se adaptem adequadamente;

3. cobrir os intermediários com a capa de proteção para impedir que resíduos se acumulem na superfície do mesmo; 
4. verificar a precisão do modelo através de um guia em resina acrílica, o qual deve ser construído um dia antes;

5. usar pinos de laboratório novos para as fases laboratoriais e para avaliar a adaptação da peça clinicamente. $O$ teste da infra-estrutura é feito com um parafuso no implante mais distal;

6. limpar a superfície de contato do cilindro de ouro com solvente de cera antes da inclusão;

7. usar capas de proteção de cilindro de ouro durante o acabamento e polimento da infra-estrutura;

8. para fundição de próteses extensas usar cilindros de ouro de $4 \mathrm{~mm}$ - a infra-estrutura será mais volumosa e firme, o mesmo ocorrendo com o guia.

Nesse mesmo ano, SORENSEN; AVERA; TOMAS ${ }^{70}$, avaliaram a fidelidade nas interfaces de diferentes sistemas. Compararam a interface implante/intermediário (I-I) e intermediário/prótese (I-P) de 4 sistemas de implante: grupo 1- 3l; grupo2 - Collagen-Osseodent; grupo 3- CollagenOsseotite; grupo 4- Nobelpharma. O cilindro de ouro foi avaliado após a confecção da infra-estrutura e aplicação de porcelana. Através de observação direta com auxílio de um microscópio com unidade de medição e aumento de $200 x$ os resultados obtidos foram grupo 1 ) $\mathrm{I}-\mathrm{I}=34 \mu \mathrm{m}$, $\mathrm{I}-\mathrm{P}=$ $48 \mu \mathrm{m}$; grupo 2) I-I = 68 $\mu \mathrm{m}, \mathrm{I}-\mathrm{P}=96 \mu \mathrm{m}$; grupo 3) $\mathrm{I}-\mathrm{I}=65 \mu \mathrm{m}$, I-P $=119 \mu \mathrm{m}$; grupo 4) $\mathrm{I}-\mathrm{I}=98 \mu \mathrm{m}, \mathrm{I}-\mathrm{P}=78 \mu \mathrm{m}$, sendo que o grupo 1 apresentou uma fidelidade de interface signifivamente melhor que os demais. Os autores concluíram que deve haver diferentes níveis de tolerância na confecção dos vários componentes de implante.

JEMT et $\mathrm{al}^{35}$, em 1992, observaram 127 próteses fixas suportadas por implantes osseointegrados Brånemark e relataram as falhas $e$ complicações das mesmas, no período de um ano após a colocação da 
prótese. Foram posicionados 354 implantes em 96 maxilas e mandíbulas, parcialmente edêntulas, de 87 pacientes, sendo que a idade variava entre 16 e 77 anos. No período de acompanhamento, o índice de sucesso dos implantes foi de $98,6 \%$ e nenhuma das próteses foi perdida. A complicação mais freqüente no primeiro ano foi relativa à perda dos parafusos de ouro em $49 \%$ das maxilas e $20,8 \%$ das mandíbulas tratadas. Houve também reclamações relacionadas à estética em menor grau.

Em 1992, MILLINGTON; LEUNG ${ }^{55}$, analisaram a possível relação entre o estresse gerado na superfície das infra-estruturas e a discrepância de adaptação. Foram criadas, através de anéis metálicos, fendas entre $6 \mu \mathrm{m}$ e $104 \mu \mathrm{m}$ em uma prótese de 4 implantes feita com ouro tipo IV. A análise fotoelástica mostrou que estresses foram induzidos com desajustes de $6 \mu \mathrm{m}$, sendo concentrados ao redor dos implantes centrais, independentemente do local onde a discrepância foi criada. Os autores observaram ainda que os estresses foram maiores, quando o desajuste estava presente no implante central, sendo que o maior estresse registrado foi na ordem de $144 \mathrm{MPa}$.

Através de um estudo simulando as condições clínicas, DELLINGES; TEBROCK $^{16}$, em 1993, avaliaram o torque aplicado aos parafusos protéticos com as chaves manuais. Simulando as condições clínicas e utilizando luvas molhadas, 60 estudantes do segundo ano foram instruídos a aplicar sua máxima força durante o aperto simulado de um parafuso. $\mathrm{O}$ valor médio do torque obtido pelo grupo masculino foi de $11,84 \mathrm{Ncm}$ e de $10,88 \mathrm{Ncm}$ para o grupo feminino, não havendo diferença estatisticamente significante entre os dois grupos. O valor médio para ambos os grupos foi de $11,55 \mathrm{Ncm}$. Nas condições estudadas, os autores concluíram que é possível obter o torque necessário para os parafusos de pequeno diâmetro $(10 \mathrm{Ncm})$ com este tipo de chave, o mesmo não ocorrendo quando os parafusos exigem um torque mais elevado. 
As dificuldades associadas com a precisão de prótese parciais fixas convencionais fundidas em monobloco, também são encontradas nas próteses implanto-suportadas. MCCARTNEY; DOUD ${ }^{52}$, em 1993, propuseram uma técnica na qual a verificação do modelo de trabalho e correções por meio de soldagens, em que se unia através de uma técnica intra-oral os cilindros de ouro e intermediários. A técnica consiste na confecção da infra-estrutura em uma peça única, mas incorporando apenas um cilindro de ouro (o mais central), enquanto que na região dos demais cilindros se encontra um orifício. Essa peça é então provada clinicamente com os demais cilindros de ouro em posição. Estes são, então, unidos à infra-estrutura através de resina tipo Duralay e esta peça é utilizada para correção do modelo mestre. Após as devidas correções, os cilindros de ouro são soldados à infra-estrutura, obtendo-se adaptação passiva com apenas uma solda. Os autores não relataram como essa adaptação passiva é avaliada clinicamente, nem os critérios para essa análise.

Nos últimos anos, o titânio tem sido um material de grande interesse na Odontologia. Devido a suas propriedades químicas, o titânio é processado diferentemente das ligas convencionais. ROGGENSACK; WALTER; BÖNING ${ }^{63}$, em 1993, investigaram as propriedades de dois métodos alternativos de união do titânio em Odontologia: soldagem a laser e soldagem de plasma. Na soldagem de plasma o arco é protegido pelo gás argônio e conduz um plasma de titânio. Foi necessária uma fenda de $500 \mu \mathrm{m}$ entre as partes e a soldagem foi feita manualmente. A dureza foi registrada para checar a influência do processo de soldagem na estrutura do metal, pois alterações da microestrutura resultam em alterações na dureza. As propriedades mecânicas das uniões soldadas foram testadas, alternando o teste de curvatura de fadiga acima de 3000 ciclos. O microscópio óptico e o traçado da dureza mostraram ampla área de aquecimento afetada após a solda com plasma comparada à solda a laser. Não houve diferenças significativas quando foi comparada, entre os dois métodos, a resistência à fadiga. Entretanto, a carga extrema leva a fadiga 
precoce das espécimes de solda com plasma. Imagens do microscópio de varredura das uniões soldadas a laser mostraram fraturas na área de soldagem, enquanto os corpos com solda de plasma fraturaram, na maior parte, distante da área de calor afetada. Com estes resultados, pode se supor que ambos os métodos são adequados para soldar titânio. Até o momento, a solda a laser é a técnica mais adequada em Odontologia, devido à sua baixa alteração térmica nas peças trabalhadas.

YAMAGISHI; ITO; FUJIMURA ${ }^{80}$, em 1993, realizaram um estudo onde placas de titânio foram soldadas com o laser Nd:YAG. As propriedades da solda foram comparadas com o titânio original. A solda a laser foi testada na atmosfera de argônio e ar. O gás argônio utilizado foi de $5 \mathrm{~L} / \mathrm{min}$. Foram realizados os testes de dobramento em 3 pontos e teste de dureza Vicker's e, para verificação da superfície, foram utilizados o microscópio de varredura e raio x para que os corpos com bolhas fossem eliminados. O microscópio de varredura mostrou falhas no centro das áreas irradiadas na atmosfera de ar, não foram observadas falhas na atmosfera de argônio, pois quando o metal é irradiado na atmosfera de argônio, é possível prevenir a oxidação que leva a falha. Nas duas atmosferas, grande força de irradiação resulta em grande resistência ao dobramento. Não se pode concluir que as propriedades mecânicas podem ser melhoradas simplesmente pelo aumento da força de irradiação, há uma relação significante entre a resistência ao dobramento, a atmosfera irradiada, a intensidade de irradiação e a combinação de atmosfera e intensidade. Por outro lado, a solda a laser foi efetiva quando na atmosfera de argônio e ao mesmo tempo, os resultados diferiram com a intensidade de irradiação. São necessárias pesquisas para determinar e identificar a melhor combinação destes dois fatores. O aumento na dureza foi menor para as peças soldadas na atmosfera de argônio do que as irradiadas no ar. 
Em um Fórum sobre assuntos atuais publicados em 1994, vários autores foram convidados a relatar como realizam o teste de adaptação da infra-estrutura de uma prótese fixa total. Segundo JEMT ${ }^{36}$, a verificação da adaptação da infra-estrutura é um dos procedimentos mais críticos durante a confecção de uma prótese implanto suportada, pois nenhuma fundição apresentará uma adaptação completamente passiva a nível micrométrico. Ele ressaltou a necessidade de uma técnica clínica, ou seja, a adaptação é checada em um nível clinicamente aceitável, onde pequenas interfaces ou fendas entre a peça fundida e os implantes, antes do aperto dos parafusos, são aceitas. Já GULBRANSEN ${ }^{23}$ ressaltou que devem ser observadas as possíveis fontes de imperfeições que existem nos procedimentos de confecção da peça protética, ou seja, os procedimentos de transferência, inclusão e fundição, propriedades das ligas e dos materiais de moldagem assim como as características dos componentes usados. Segundo PAREL $^{58}$, a obtenção de peças com adaptação passiva ainda é irreal, e embora haja vários métodos para melhorar os procedimentos de fundição, assim como o de confecção da prótese como um todo, a maneira de se avaliar clinicamente o produto final desses procedimentos, em termos de passividade, permanece relativamente sem qualquer base científica. Desse modo, ele acredita que a melhor forma de avaliar a adaptação é através da inspeção visual e da utilização do parafuso, ou seja, apertar o parafuso mais distal e observar a adaptação do outro lado da peça. Esta técnica é facilmente utilizada em laboratório e deve ser repetida clinicamente, embora não seja efetiva quando a área a ser examinada se encontra subgengivalmente localizada. Neste caso, o autor recomenda observar a quantidade de voltas necessárias para apertar totalmente o parafuso e, se um parafuso exige mais voltas, isso pode ser indicativo de um desajuste vertical. Os autores também salientaram a necessidade de se verificar a fidelidade do modelo obtido - este procedimento é fundamental para obtenção de uma peça bem adaptada e permitir a verificação da adaptação já no próprio modelo. 
Muitos problemas relacionados aos parafusos do intermediário e do cilindro de ouro podem ser resultado de um apertamento impróprio. GOHEEN et $\mathrm{al}^{19}$, em 1994, avaliaram a capacidade de cirurgiões e protesistas em aplicar o torque adequado, usando chaves manuais, em diferentes períodos do dia. Os autores também avaliaram a quantidade de torque aplicado pelos torquímetros eletrônicos. Os resultados mostraram que há uma grande variação na aplicação do torque, sendo que o torque aplicado pelos cirurgiões foi significativamente inferior aos valores desejados de 10, 20 e $30 \mathrm{Ncm}$, tanto no período da manhã como à tarde. Já o torque aplicado pelos protesistas foi significativamente inferior para o valor de $10 \mathrm{Ncm}$ no período da tarde e para o valor de $32 \mathrm{Ncm}$, em ambos os períodos. $\mathrm{Na}$ análise dos torquímetros, todos os valores de torque experimentais estavam dentro da tolerância especificada pelos respectivos fabricantes, exceto para o Torque Controller Nobelpharma a $10 \mathrm{Ncm}$ e $32 \mathrm{Ncm}$ com baixa velocidade e $20 \mathrm{Ncm}$ com alta velocidade. Os torquímetros avaliados foram: Brånemark Torque Drivers $10 \mathrm{Ncm}$ em alta $\mathrm{e}$ baixa velocidade; Accu-Torque Wrench e Implant Innovations Torque Driver com $10 \mathrm{Ncm}$ e $20 \mathrm{Ncm}$. Os dados indicam que há uma grande variedade na habilidade dos clínicos em perceberem a força adequada de torque aplicada aos componentes de implante.

Através de uma análise fotoelástica, WASKEWICKZ; OSTROWSKI; PARKS $^{78}$ (1994) compararam os padrões de estresses gerados em torno dos implantes com uma infra-estrutura adaptada e não adaptada. Um modelo fotoelástico simulando a curva da mandíbula foi construído com 5 implantes Nobelpharma $(3,75 \mathrm{~mm} \times 10 \mathrm{~mm})$ e com intermediários convencionais de $4 \mathrm{~mm}$ de diâmetro(Nobelpharma). Sobre esse conjunto, foram posicionados os cilindros de ouro que, após torque de $10 \mathrm{Ncm}$, foram unidos entre si com resina autopolimerizável para confecção da infraestrutura em liga de ouro-paládio. Após a fundição, a infra-estrutura foi colocada no modelo e não havia um contato íntimo entre os intermediários e os cilindros de ouro. Esta infra-estrutura não passiva foi analisada 
fotoelasticamente pelo apertamento dos parafusos de ouro com $10 \mathrm{Ncm}$ por 3 seqüências diferentes de aperto dos parafusos. Após uma avaliação inicial, a infra-estrutura foi seccionada entre cada intermediário, ou seja, em 4 partes. Os resultados mostraram que a infra-estrutura não adaptada gerou uma concentração de estresse em torno dos implantes, independente da seqüência do aperto. Os cinco implantes apresentaram franjas, mas os implantes 1 e 5 (extremos) mostraram a maior concentração de estresse no terço médio de cada implante e a menor na região apical e cervical. Quando a infra-estrutura foi seccionada e soldada, uma relação passiva com os intermediários foi encontrada sem estresse nos implantes. Os autores acreditaram que, quando se tem uma prótese sem adaptação passiva é recomendável que as peças sejam seccionadas e soldadas para obter-se uma adaptação o mais passiva possível.

CARLSSON $^{7}$ (1994) ressaltou a importância da obtenção de próteses com adaptação passiva. Uma prótese com adaptação passiva significa que pode ser parafusada sem causar estresse ou tensão, porém não existe uma adaptação absolutamente passiva já que todo aperto de parafusos gera uma certa deformação da prótese e/ou do osso, introduzindo algum estresse ao sistema. O estresse e tensão, resultados de uma prótese mal adaptada, são fatores que afetam significativamente a longevidade dos componentes. Segundo o autor, existem duas formas de medir o grau de desadaptação de um sistema: medir as forças que são introduzidas durante o aperto dos parafusos ou medir a extensão dessa desadaptação através de um microscópio de medição. O autor relatou ainda que, devido às características do Sistema Brånemark, uma desadaptação lateral de $50 \mu \mathrm{m}$ não gera qualquer tensão ao sistema, mas um erro angular de mesma dimensão é capaz de gerar um deslocamento angular no ápice do implante para aliviar a tensão gerada. A precisão de adaptação entre o intermediário do implante e o componente protético da infra-estrutura tem sido questionada como sendo um fator significante na transferência do 
estresse, biomecânica dos sistemas de implante, ocorrência de complicações e resposta dos tecidos na interface biológica.

GYLLENRAM $^{24}$, analisando os parâmetros clínicos para avaliar a adaptação passiva da prótese implanto-suportada, comentou que qualquer desadaptação gera forças estáticas que vão atuar sobre todo o conjunto e esses efeitos negativos serão acentuados, quando as forças dinâmicas da mastigação atuarem sobre esse mesmo conjunto. Em um osso mais resistente, um certo grau de desadaptação pode ser melhor tolerado que em um osso esponjoso, assim como na região posterior da maxila, que, além de menos volumoso, também é sujeito a maiores forças durante a mastigação. A desadaptação pode ser de 3 tipos: vertical, horizontal e angular. Um erro vertical leva a uma desadaptação que é proporcional ao erro; o erro horizontal pode levar a duas situações diferentes, dependendo do grau de desadaptação e do tipo de implante que está sendo usado. No caso do sistema Brånemark, que apresenta um grau de liberdade horizontal entre o cilindro de ouro e o intermediário, uma desadaptação que não ultrapasse esse grau de liberdade horizontal não será prejudicial ao sistema; em outras situações, onde não existe essa liberdade horizontal, qualquer desadaptação horizontal leva a uma combinação de desadaptação horizontal e angular. A desadaptação angular é séria, porque seus efeitos são acentuados à medida que o grau de desadaptação é igual, pois existem diferenças funcionais fundamentais. Em uma boa moldagem ainda há a possibilidade de um erro de $50 \mu \mathrm{m}$ em todos os eixos, assim, em um sistema com uma adaptação melhorada, ou seja, onde todas as faces internas do cilindro de ouro se adaptam perfeitamente ao intermediário, esse grau de adaptação pode gerar não apenas um erro horizontal, mas um erro angular 3 vezes maior.

HULTERSTRÖM; NILSSON ${ }^{30}$, em 1994, realizaram um trabalho onde 66 pacientes receberam próteses fixas sobre implantes com infra- 
estruturas fabricadas em cobalto-cromo. Nas infra-estruturas, parte da face lingual, vestibular e proximais foram realizadas em cobalto-cromo e as outras partes foram realizadas em resina acrílica. A ligação entre a infraestrutura metálica e o cilindro de ouro foi realizada de três maneiras. No grupo 1, os cilindros foram unidos à infra-estrutura com resina acrílica autopolimerizável. No grupo 2, os cilindros foram parcialmente soldados à infra-estrutura combinado com resina acrílica e, no grupo 3, os cilindros foram completamente soldados à infra-estrutura. As próteses foram analisadas por um período de 6 meses a 3 anos e nenhuma complicação que poderia ser atribuída ao material utilizado foi vista. O cobalto-cromo é um material conveniente para infra-estruturas de próteses fixas implantosuportadas, em casos onde não há problemas estéticos, preferivelmente, nos casos de mandíbula totalmente edêntula.

BERG et al $^{3}$, em 1995, compararam as propriedades mecânicas de fundição do titânio e seu desempenho, quando trabalhado nas condições de soldagem a laser e sem união. As propriedades do ouro tipo IV fundido e soldado foram incluídas como controle, pois as propriedades físicas deste material e este método são conhecidos. As barras de titânio foram soldadas a laser e a liga de ouro com solda de alta fusão. Todas as barras foram testadas em tração com a máquina de teste universal (Instron Corp., Canton, Mass.) numa velocidade de $0,5 \mathrm{~mm} / \mathrm{min}$. A resistência à tração, $0,2 \%$ resistência do produto, e a porcentagem de alongamento foram registradas. Ambos os métodos de união reduziram significantemente a ductibilidade do material. A resistência da liga de ouro fundido foi superior a do titânio. Entretanto, a resistência do titânio soldado a laser eqüivaleu à solda forte da liga de ouro, que sugere que as restaurações dentárias fundidas e de titânio trabalhado satisfaria ordenadamente os requisitos clínicos. 
Em 1995, ISA; HOBKIRK ${ }^{32}$, avaliaram, in vitro, os efeitos causados pelo aperto dos parafusos de ouro em uma prótese de 5 elementos, assim como, os efeitos de se parafusar próteses com diferentes graus de desajuste. Os resultados mostraram que o aperto de cada parafuso de ouro produziu altas forças compressivas, mesmo quando as próteses não apresentavam um desajuste aparente e que essas forças não eram igualmente distribuídas nem tampouco consistentes. Quando diferentes graus de desajuste foram criados na interface intermediário/cilindro de ouro, observou-se que forças de tensão eram produzidas mesmo em desajustes tão pequenos quanto $10 \mu \mathrm{m}$.

Com o objetivo de medir a adaptação entre as próteses de titânio soldadas e o modelo mestre, antes da conexão com os implantes, e comparar estas medidas com a adaptação precisa das infra-estruturas fundidas com liga de ouro em situações similares, JEMT ${ }^{37}$, em 1995, realizou uma pesquisa. Um total de 30 próteses fixas suportadas por implantes Brånemark em mandíbulas inferiores edêntulas foram medidas utilizando uma técnica fotogramétrica. Os pacientes foram dispostos em três grupos diferentes de acordo com o desenho da infra-estrutura. No grupo I, 10 pacientes receberam infra-estruturas com liga de ouro fundidas em monobloco e os outros dois grupos receberam infra-estruturas de titânio fundido com desenhos diferentes. Foi realizado o aperto de um parafuso terminal para observar a adaptação das próteses no lado oposto. Medidas da distorção tridimensional em relação ao modelo mestre foram realizadas. A menor distorção foi observada em direção vertical nos três grupos. Não houve diferença estatisticamente significante entre os grupos com relação à adaptação.

KANO et $a^{43}$, em 1995, avaliaram a adaptação de infra-estruturas fundidas a partir do componente calcinável do 3l (Implant Inovations) comparada à adaptação obtida com o cilindro de ouro Nobelpharma. Os 
resultados obtidos foram: $117 \mu \mathrm{m}$ para o cilindro de ouro Nobelpharma; $132 \mu \mathrm{m}$ para a matriz plástica fundida em liga Pors-On 4 (Degussa Hülls); $135 \mu \mathrm{m}$ para a matriz plástica antes da fundição; $156 \mu \mathrm{m}$ para a matriz plástica fundida em liga de niquel-cromo e $224 \mu \mathrm{m}$ para a fundição com a liga Palliag M (Degussa Hülls).

Muitos problemas estão associados ao uso de titânio e suas ligas em prótese. Devido à grande afinidade do titânio com o oxigênio e sua rápida reação a altas temperaturas, os métodos de soldagem convencionais que usam chama de oxigênio ou maçarico não são indicados para unir esses materiais. O gás inerte de tungstênio, soldagem a laser e soldagem com radiação infravermelha pelo método de aquecimento têm sido usados para unir metais. Eles são adequados para unir próteses de titânio, porque o calor intenso pode ser gerado por esses métodos em um curto período de tempo. Sendo assim, WANG; WELSCH ${ }^{77}$, em 1995, examinaram a qualidade e as propriedades mecânicas de espécimes de titânio e Ti-6Al$4 \mathrm{~V}$ que haviam sido unidos por 3 diferentes processos: soldagem com gás inerte de tungstênio; soldagem a laser e soldagem com radiação infra vermelha pelo método de aquecimento. Para cada grupo experimental foram utilizadas 16 barras de titânio e 16 barras de Ti-6Al-4V. Barras originais que não receberam o procedimento de união serviram como controle. Um total de 8 grupos e 64 amostras foram incluídos neste estudo. Testes mecânicos e análise da microestrutura foram usadas para avaliar as amostras unidas. Os testes mecânicos incluíram microdureza Vickers; teste de tração uniaxial de resistência das uniões e porcentagem de alongamento. A ruptura na tração ocorreu na região de união de todas as amostras por falha coesiva. As amostras das ligas de Ti-6Al-4V exibiram resistência à tração significativamente maior do que as amostras de titânio puro. Amostras preparadas pelos 3 métodos de união tiveram marcadamente mais baixa tração de alongamento do que o titânio controle e as barras de Ti-6Al-4V. As mudanças na microestrutura e microdureza foram estudadas nas áreas afetadas e não afetadas pelo calor. Os valores 
de microdureza aumentaram na área afetada pelo calor para todos os corpos testados.

BERGENDAL; PALMQVIST ${ }^{4}$, em 1995, avaliaram o desempenho clínico de próteses fixas sobre implantes com infra-estruturas de titânio soldadas a laser. Participaram deste estudo 19 centros de prótese experientes da Suécia. 93 pacientes com 100 próteses fixas sobre implantes foram incluídas e acompanhadas por um período de 2 anos. As infra-estruturas de titânio foram desenhadas e produzidas de acordo com o sistema Procera. Os resultados deste grupo foram comparados com 0 grupo controle que incluiu 91 pacientes com 96 próteses fixas sobre implantes. Neste grupo, as infra-estruturas foram fundidas com uma liga altamente nobre com exceção de um centro que utilizou uma liga de Co-Cr. Os autores observaram que $81 \%$ das próteses sobre implantes com infraestruturas de titânio foram julgadas como excelentes. Somente $11(1,2 \%)$ dos 946 implantes que suportavam as próteses fixas tinham sido perdidos ou não estavam integrados no período de acompanhamento; 8 de 485 implantes $(1,6 \%)$ no grupo com infra-estrutura de titânio, e 3 dos 461 implantes $(0,7 \%)$ no grupo controle. Uma infra-estrutura de cada grupo tinha fraturado. Houve uma tendência maior de fratura dos dentes artificiais e resina acrílica no grupo com infra-estrutura de titânio, quando comparados com o grupo controle. Uma possível explicação pode ser feita com relação aos técnicos dos diferentes centros não estarem familiarizados com o tipo e desenho das infra-estruturas de titânio quando o estudo se iniciou.

Uma nova tecnologia chamada "Procera" foi introduzida no mercado como um método alternativo para a fabricação de próteses sobre implantes. A técnica consiste na união de componentes de titânio puro prémaquinados pelo uso de uma técnica chamada soldagem estereolaser. RUBENSTEIN ${ }^{64}$, em 1995, apresentou os resultados de 10 pacientes que 
foram tratados com a tecnologia Procera e acompanhados por um período de 1 ano. A soldagem estereolaser é considerada uma técnica que pode reduzir ou eliminar a distorção na fabricação de infra-estruturas. Nenhuma diferença significante foi observada entre os pacientes com infra-estruturas convencionais de ouro. Enfatizou que estudos por um período mais longo de tempo são necessários para comprovar a eficácia desta técnica.

Muitas técnicas têm sido relatadas para a fabricação de infraestruturas com adaptação precisa e passiva. THOUPOS et al $^{75}$, em 1995 , descreveram uma técnica que substitui a soldagem durante a fabricação de infra-estruturas de próteses sobre implantes do arco todo para evitar possível distorção. A técnica tem sido usada para unir as secções e reparar próteses fixas convencionais fundidas com ligas não preciosas. De acordo com os autores, esta técnica apresenta algumas vantagens com relação à técnica de soldagem convencional: (1) a distorção da posição das partes da infra-estrutura durante a fundição é menor que a técnica de soldagem; (2) o metal selecionado para a fabricação da infra-estrutura dos implantes é usado para unir as partes; (3) é possível ter um maior controle da quantidade, posição e fluidez do metal; (4) retenções mecânicas podem ser usadas; (5) a necessidade de soldagem é eliminada.

CARR et $\mathrm{al}^{9}$, em 1996, mediram e compararam a pré-carga produzida quando se utilizam cilindros de ouro, cilindros produzidos a partir de cilindros de ouro pré-fabricados, cilindros de plástico fundidos e cilindros de plástico fundidos após acabamento e polimento. Foram utilizados cilindros de ouro e plástico compatíveis com o intermediário SDCA 004 Nobelbiocare (Nobelbiocare USA, Chicago). Para a fundição foram utilizadas ligas de alta e baixa fusão para verificar a influência da temperatura na medida da pré-carga. Os resultados revelaram uma précarga significativamente mais alta nos cilindros metálicos, quando comparados com os produzidos a partir de cilindros de plástico. No grupo 
dos cilindros de plástico, a liga da baixa fusão produziu uma pré-carga significativamente mais alta que a liga de alta fusão. Analisando os efeitos do acabamento e polimento, houve um aumento significante na pré-carga dos cilindros de plástico; já nos cilindros metálicos este aumento não foi observado.

Neste mesmo ano de 1996, JAARDA; RAZZOOG; GRATTON ${ }^{33}$, avaliaram a compatibilidade de alguns parafusos de ouro disponíveis no mercado. Foram testados 5 parafusos (ouro e titânio) de 3 marcas comerciais: 3I (Implants Inovations); ImplaMed; Implant Support Systems tendo os parafusos Nobelpharma como controle. Os parafusos de ouro foram rosqueados a um torque de $10 \mathrm{Ncm}$ através de um torquímetro. Quando a variabilidade entre-sistema não era maior que a variabilidade intra-sistema, o parafuso era considerado compatível. $O$ teste de resistência à tração foi realizado, sendo que os parafusos receberam carga até sua fratura. Todos os parafusos foram significativamente diferentes quando comparados ao Nobelpharma e quando comparados entre si, exceto os parafusos de ouro 3I (Implants Inovations) e ImplaMed que não mostraram diferença significante, quando comparados entre si. Houve também grande variabilidade nos resultados em relação ao tipo de liga utilizada. Os autores concluíram que a grande variabilidade entre os diferentes parafusos testados em relação a resistência à tração pode influenciar o sistema.

Em 1996, JEMT ${ }^{39}$, avaliou medidas obtidas a partir de modelos, comparando-as com aquelas obtidas diretamente na cavidade oral, com o intuito de verificar os métodos que produzissem os maiores graus de adaptação das próteses sobre implantes. As análises foram realizadas através do método fotogramétrico computadorizado que fornece medidas tridimensionais. O objetivo da comparação foi verificar a validade dos vários estudos onde são usados modelos como referência devido a 
dificuldade de realização de estudos in vivo. Foram selecionados 17 pacientes, sendo 10 com implantes em mandíbula e 7 em maxila, e os modelos de trabalho obtidos com os cuidados habituais. As próteses foram confeccionadas através de 2 métodos. Cinco foram fabricadas em titânio (Ti-3 frames, Procera, Nobelpharma AB, Göteborg, Sweden) e soldadas a laser e as outras doze foram fabricadas em ouro através do processo de fundição em monobloco. Todas foram clinicamente testadas e aceitas como adaptadas satisfatoriamente. As análises mostraram resultados diferentes para as diversas situações. Quando os modelos foram usados como referência, a média tridimensional de distorção do ponto central do cilindro de ouro foi de $37 \mu \mathrm{m}$ nas próteses mandibulares e de $75 \mu \mathrm{m}$ nas próteses maxilares. Quando as medidas foram realizadas diretamente na cavidade oral, os valores eram de $51 \mu \mathrm{m}$ nas próteses mandibulares e de $111 \mu \mathrm{m}$ para as maxilares. A média de desajuste tridimensional foi significativamente maior para as medidas realizadas in vivo. Os autores lembram que as próteses tinham sido consideradas satisfatórias pelos testes clínicos habituais e alertam que as próteses com "aparência" aceitável podem possuir centenas de mícrons na interface de desadaptação e que, como interfaces deste nível podem causar problemas, é uma questão que requer investigação.

A preocupação em desenvolver sistemas fiéis e reproduzíveis para avaliar e mensurar a adaptação dos componentes de implantes, levou alguns centros a desenvolverem seu próprio sistema de medição. JEMT ${ }^{38}$, et al (1996) apresentaram os resultados dos métodos e sistemas desenvolvidos para mensurar a adaptação na interface componente protético/intermediário. Este estudo foi realizado em 4 centros dos Estados Unidos e Suécia por um período de 2 anos. Foram desenvolvidos 4 sistemas de medição, todos capazes de dar dados tridimensionais que quantificam as relações linear e angular. Todos os sistemas são ligados a computadores com programas para transformações geométricas, análises estatísticas e resumo das informações diretamente em gráficos. Após 
todas as análises, concluíram que há diferenças entre os 4 sistemas e que é importante que sejam desenvolvidos métodos precisos e confiáveis de avaliação devido à importância clínica do fator adaptação protética.

HANEY; MEIERS ${ }^{25}$, em 1996, mediram o calor conduzido através do titânio puro, com o intuito de determinar se o calor gerado seria aceitável para garantir a vitalidade pulpar do dente pilar. Foi utilizado um aparelho de soldagem intra-oral disponível no mercado. 4 próteses simulando uma PPF de 3 elementos foram construídas para serem soldadas em titânio puro $(99,96 \%)$ fundido. Cada espécime foi sujeita a 10 soldas. Os eletrodos foram mantidos na mesma posição da união durante toda a solda de cada espécime. Em cada uma das 4 próteses, a alteração mínima de temperatura foi após um simples pulso com força total e o pico máximo foi após 3 pulsos com força total. A temperatura registrada com a soldagem intra-oral foi consideravelmente mais baixa que $527^{\circ} \mathrm{F}$ e dissipou rapidamente para um nível abaixo do qual produz um dano irreparável à polpa. As baixas temperaturas registradas na soldagem $\left(3,034^{\circ} \mathrm{F}\right)$ reflete a baixa condutibilidade térmica do Ti de $32 \mathrm{mcal} / \mathrm{seg} / \mathrm{cm} /{ }^{\circ} \mathrm{C} / \mathrm{cm}^{2}$.

Um método simplificado para medir espécimes bi ou tridimensionais foi apresentado por KARELLOS et $\mathrm{al}^{45}$, em 1996. Disto resultou uma técnica a qual permite que as medições sejam realizadas diretamente sobre as fotomicrografias, com uma régua transparente, em um método barato e preciso. A técnica utiliza um microscópio no aumento desejado, com uma câmara de $35 \mathrm{~mm}$ acoplada à ocular do microscópio. Uma régua de $2 \mathrm{~mm}$ com divisões de $10 \mu \mathrm{m}$ é fotografada no aumento desejado. Através de um programa de computador cria-se uma régua de $20 \mathrm{~cm}$ a partir da imagem obtida da régua de $2 \mathrm{~mm}$. Essa régua de $20 \mathrm{~cm}$ é impressa em transparência e recortada, sendo assim utilizada para medir as áreas desejadas nas fotomicrografias. 
As propriedades mecânicas elásticas foram estudadas por NEO et $\mathrm{al}^{56}$, em 1996, e o titânio intacto foi usado como controle. Uniões soldadas foram fabricadas com técnica de solda a laser estereográfica ou arco de gás tungstênio. O efeito de tratamento com calor após a aplicação da porcelana foi simulado e também investigado. Soldas a laser tratada com aquecimento tiveram significantemente mais baixa resistência a tensão. $O$ aquecimento não teve efeito no módulo de elasticidade ou alongamento, mas geralmente diminui significativamente a resistência do produto nas espécimes de titânio. Os corpos soldados com gás tungstênio tiveram significativamente mais alta resistência e módulo de elasticidade do que os outros 2 grupos. O alongamento dos espécimes-controle foi significativamente maior do que o alongamento dos espécimes soldados com gás tungstênio, o qual foi em ordem significativamente mais alto que os espécimes soldados com laser.

ZOIDIS; WINKLER; KARELLOS ${ }^{82}$, em 1996, investigaram o efeito de três técnicas de união, soldagem, soldagem eletrônica e soldagem com a própria liga. 30 barras de implante foram confeccionadas no modelo mestre sobre 2 análogos de intermediário. As barras foram fundidas em ouro tipo IV. A partir daí, as barras foram seccionadas e a adaptação da cada interface cilindro de ouro/intermediário foram analisadas usando um estereomicroscópio. Os cilindros de ouro foram parafusados nos seus respectivos intermediários com um torque recomendado de $28,2 \mathrm{Ncm}$. $\mathrm{O}$ procedimento de união com a própria liga foi não somente o mais preciso, mas também a mais consistente das técnicas. Segundo os autores a ausência de um material fundido entre as partes durante a soldagem pode ser um dos fatores responsáveis por estes resultados. Nenhuma das técnicas testadas resultaram em uma adaptação aceitável. A soldagem a laser ou fundição em monobloco podem ser usadas como uma técnica alternativa. 
MAY et $\mathrm{al}^{49}$, em 1997, descreveram um método para avaliar a precisão de adaptação dos componentes de implante. A precisão de adaptação é essencial para a longa vida do implante dental e preservação do osso de suporte. Os métodos mais utilizados para avaliar a precisão dos componentes dos implantes são a percussão, observação visual e radiografias periapicais convencionais. O desenvolvimento de um método para identificar e quantificar a imprecisão clinicamente é válido e necessário. Os autores utilizaram o instrumento Periotest (Siemens, BioResearch Inc., Milwaukee, Wis.), para avaliar a estabilidade das interfaces entre o implante e o intermediário e entre o intermediário e o cilindro de ouro sob uma série de condições. O Periotest consiste em um bastão controlado eletronicamente, conduzido eletromagneticamente, que se move rapidamente na superfície do dente em um ângulo de $90^{\circ}$, numa velocidade de 4 ciclos por segundo. O tempo de contato entre a haste e 0 dente é registrado pelo instrumento e o valor numérico aparece na tela do aparelho. Este valor é registrado como valor Periotest (PTV). Este valor representa a medida quantitativa do grau de movimento do objeto submetido a um estímulo percussão. Este instrumento tem sido utilizado para avaliar a condição periodontal dos dentes naturais e alterações funcionais dos tecidos periodontais e do osso. Quanto mais negativo for o PTV maior será a resistência ao movimento e, quanto mais positivo, menor. Os autores testaram a hipótese de que o valor mais negativo do Periotest, indicaria uma adaptação precisa e o valor mais positivo estaria relacionado com a imprecisão de adaptação. Para esta investigação foram utilizadas duas costelas bovinas para simular o paciente. Em cada uma foram colocados 3 implantes Branemark auto-rosqueáveis com distâncias de 7 a $10 \mathrm{~mm}$ entre si e em curva. Uma série de condições experimentais de adaptação e desadaptação foram criadas para testar a validade do método. A primeira medida foi realizada com os cilindros de ouro aparafusados; a segunda foi realizada com os cilindros desajustados na ordem de 25,4 $\mu \mathrm{m}$, $50,8 \mu \mathrm{m}$, e 101,6 $\mu \mathrm{m}$ e apertados com torque mecânico de $20 \mathrm{Ncm}$. Os resultados encontrados mostraram que os valores aumentavam 
proporcionalmente à desadaptação nos cilindros, ou seja, desadaptações nas margens dos cilindros de ouro causam instabilidade. Os autores relatam que isso pode ser explicado se analisarmos as superfícies internas dos componentes. A superfície superior da interface do intermediário é composta por uma superfície de contato externo plana e uma parte elevada central, cônica. Se existe contato entre as partes internas opostas (superfície interna do cilindro de ouro com a parte cônica do intermediário) a carga acontece entre as duas superfícies dos dois componentes.

A adaptação desses componentes no plano horizontal permite algum movimento na colocação do cilindro de ouro, antes do procedimento de aperto do parafuso. A altura vertical, no entanto, é preservada. O erro de adaptação da superfície basal pode levar à maior instabilidade. O menor diâmetro e a metalurgia do parafuso de ouro é outro fator que leva à instabilidade porque o parafuso do intermediário é muito mais rígido. Os autores concluíram que: (1) os intermediários e os cilindros de ouro têm diferentes PTVs; (2) o instrumento Periotest pode ser usado para quantificar a adaptação das interfaces dos componentes; (3) o desajuste entre o implante e o intermediário não afeta tanto a estabilidade. Portanto, o desajuste entre o intermediário e o cilindro pode produzir instabilidade significante que aumenta linearmente com o grau de desajuste.

Neste mesmo ano, RIEDY et $\mathrm{al}^{62}$, avaliaram in vitro a precisão de adaptação de infra-estruturas sobre implantes usando a técnica Procera com videografia laser. A média da interface do eixo $z$ no ponto central serviu como critério para avaliação da adaptação das infra-estruturas com os intermediários dos implantes. Os resultados deste estudo mostraram que a infra-estrutura soldada a laser exibiu uma adaptação mais precisa que a fundição em monobloco.

A overdenture implanto-suportada é uma solução para os problemas de pacientes edêntulos tanto na maxila quanto na mandíbula. 
PAVLATOS ${ }^{60}$, em 1997, apresentou um caso clínico de overdenture sobre implante na mandíbula, no qual foram utilizados 3 implantes com forma de raiz (Innova Implant System). Destes implantes, 2 foram colocados na região de canino e um próximo à região de incisivos. Na segunda etapa cirúrgica foram conectados os intermediários e a osseointegração foi clinicamente e cirurgicamente confirmada. A partir daí, foi realizada a moldagem para transferência da posição dos implantes em boca para o modelo de trabalho. Sobre o modelo foram realizados 5 tipos de overdentures: 1) intermediário com encaixe do tipo bola com retenção o'ring; 2) barra simples e clip; 3) barra tipo Dolder com encaixe tipo Era nos intermediários distais para prótese parcial; 4) barrazaag baixo perfil; 5) conecção intragengival com intermediário do tipo zaag. O zaag implant anchor/intragengival connection foi a overdenture implanto-suportada eleita para o paciente. Vários desenhos protéticos podem ser realizados para melhorar a estabilidade e a retenção das overdentures.

As propriedades mecânicas das soldas a laser do titânio comercialmente puro sob diferentes condições de soldagem a laser foram avaliadas por $\mathrm{CHAl}$; $\mathrm{CHOU}^{10}$, em 1998, para encontrar os parâmetros ótimos em termos de duração e voltagem. 57 corpos fundidos em titânio puro de acordo com a especificação ISO 6871 foram divididos em 9 grupos experimentais e um grupo controle. As barras de titânio seccionadas foram soldadas com laser sob diferentes durações (8, 10 e 12ms) e níveis de energia $(290,300$ e $310 \mathrm{~V})$ e avaliadas para classificar a resistência a tensão (374, a 562MPa), $0,2 \%$ do produto da resistência (YS) (206 a $338 \mathrm{MPa})$ e porcentagem de alongamento $(2,49 \%$ a $10,58 \%)$. A resistência máxima a tensão(UTS) melhora com o aumento de impurezas de nitrogênio e oxigênio, que será acompanhada pelo decréscimo na ductibilidade e fragilidade, portanto o titânio deve ter somente 0,4 a $0,5 \%$ de impurezas. A força da unidade soldada a laser poderia ser controlada e determinada por 2 parâmetros : voltagem e duração de pulso. A voltagem controla a energia de soldagem e um aumento na voltagem conduz a maior profundidade de 
soldagem. Dos resultados das médias de valores das propriedades mecânicas e o número de áreas fraturadas, $300 \mathrm{~V} / 12 \mathrm{~ms}$ resultou ótimas condições de soldagem. Nessas condições, provavelmente forneceu quantidades adequadas de nitrogênio e oxigênio na área de solda para permitir as melhores propriedades físicas. A voltagem foi o único fator significante que influenciou a resistência a tensão(UTS) e a resistência do produto(YS) da união. A duração não foi fator significante para a resistência da união soldada a laser. Se as condições de soldagem a laser são adequadas, as barras de titânio soldadas não serão friáveis ou sua elasticidade superior perdida.

Observando a freqüência de afrouxamento dos parafusos de ouro McGLUMPHY; MENDEL; HOLLOWAY ${ }^{54}$, em 1998, oferecem soluções práticas para minimizar este problema clínico. Muitos produtos, componentes e técnicas têm sido sugeridas para manter o parafuso estável. Estas sugestões incluem rosca antivibracional, interligação mecânica direta, alterações no desenho do parafuso, e mecanismo de controle de torque. Todas estas idéias têm ajudado a minimizar o problema de afrouxamento do parafuso, mas nenhuma tem eliminado o problema completamente. O afrouxamento do parafuso pode causar maiores problemas, tais como perda óssea ou fratura do implante. Existem dois fatores envolvidos na conservação do parafuso do implante apertado: (1) aumentar a força de travamento, e (2) diminuir as forças de separação.

Para conseguir uma união segura, os parafusos devem ser tensionados para produzir uma força de travamento maior que a força externa que tende a separar. No desenho de um parafuso de junta rígida, o mais importante do ponto de vista funcional é a força de travamento inicial desenvolvida pelo apertamento do parafuso. A força de travamento é usualmente proporcional ao torque. Um pequeno torque pode permitir a separação da união e resultar na fadiga do parafuso ou afrouxamento. Um grande torque pode causar falha do parafuso ou tirar a rosca do parafuso. 
Aplicado, o torque desenvolve uma força dentro do parafuso chamada précarga que é uma carga inicial no parafuso em tensão. Esta força de tensão no parafuso desenvolve uma força compressiva de travamento entre as partes. Entretanto, a pré-carga do parafuso é igual à força de travamento em magnitude. A pré-carga é determinada pelos seguintes fatores:

1- Torque aplicado

2- Liga do parafuso

3- Desenho da cabeça do parafuso

4- Liga do intermediário

5- Superfície do intermediário

6- Lubrificante

O torque é controlado pela resistência mecânica do parafuso e o modo como é aplicado. O valor do torque ótimo pode ser calculado pelo apertamento do parafuso até que ele falhe. $75 \%$ deste valor é um torque ótimo para aplicar no parafuso. Desta maneira, uma força de travamento significante pode ser desenvolvida com o mínimo risco de fratura do parafuso.

Os incidentes de afrouxamento de parafuso aumentam se uma infraestrutura não passiva é forçada a se adaptar pelo apertamento do parafuso. A infra-estrutura original aplica forças de separação da união com o sistema devido à tentativa de retornar à posição original. Todas as infra-estruturas não passivas devem ser seccionadas e soldadas para garantir uma adaptação passiva.

Em 1998, WANG, $\mathrm{CHANG}^{76}$, explicaram a razão do fenômeno de profundidade de solda superficial e extenso dano à superfície usando transferência numérica de calor simulado para o titânio puro. Nos casos onde utilizaram ouro puro foi realizado uma análise comparativa e o método alternativo de múltiplos pulsos também foi examinado pela 
soldagem a laser para o titânio puro. Uma diferença da análise finita unidimensional foi usada para simular a transferência de calor no titânio puro e no ouro durante a soldagem a laser com um programa de software construído para o consumidor. A profundidade de penetração é referente à distância da superfície de titânio não danificada original à superfície abaixo a que o titânio foi soldado pela energia a laser. O perfil de gradiente térmico do ouro demonstrou melhor penetração e provou que aumentando a força do laser, aumentou o dano na superfície de ouro também, mas a profundidade de soldagem foi 6 vezes maior quando comparada com os casos de titânio. Com irradiação no titânio de pulso simples, um aumento na força não pode aumentar grandemente a profundidade de derretimento. O excesso de energia somente vaporiza a superfície do material.

Para minimizar os erros e otimizar trabalhos com adaptação passiva, HELLDÉN; DÉRAND ${ }^{26}$ (1998) apresentam as vantagens obtidas com o método "Cresco Ti Precision" para a execução da próteses em titânio, soldadas a laser. Em um modelo fotoelástico foram colocados 3 implantes (Cresco Ti Systems $\mathrm{AB}$ ) de $13 \mathrm{~mm}$ e sobre estes foram enceradas 4 próteses a partir de cilindros de plástico. As peças foram incluídas e fundidas em titânio comercialmente puro através do uso de uma máquina de fundição. Duas próteses foram submetidas ao método de precisão e as outras duas, não. As próteses não adaptadas foram observadas ao microscópio e foram encontradas interfaces no sentido vertical de $70 \mu \mathrm{m}$ e $40 \mu \mathrm{m}$ nos implantes A e B. Foram realizadas análises fotoelásticas e também medidas as cargas exercidas através de mecanismos apropriados. Os resultados revelaram cargas associadas às próteses não adaptadas e ausência de cargas estáticas nas próteses adaptadas. No momento de medição das cargas, foram encontrados valores de $41 \pm 4,3 \mathrm{~N}$ nos parafusos para que os mesmos conseguissem fechar interfaces de $180 \mu \mathrm{m}$ nos implantes distais. Para fechar $30 \mu \mathrm{m}$, foram encontradas cargas de $8 \pm$ $8,0 \mathrm{~N}$. Nas próteses adaptadas a carga encontrada nos parafusos foi zero. Para interfaces de $50 \mu \mathrm{m}$, localizadas no implante central, foi encontrada 
carga de $300 \pm 26 \mathrm{~N}$ no parafuso de ouro. Os autores ressaltam a importância do fato de que os estresses dependem do erro, da dimensão do mesmo, assim como do tamanho da peça e da localização do mesmo. Consideram também que, apesar do efeito do erro estar relacionado a outros fatores como, por exemplo, qualidade óssea, há de se lembrar sempre da importância da adaptação da peça na geração das cargas.

BERGENDAL; PALMQVIST ${ }^{5}$, em 1999, publicaram os resultados de um estudo longitudinal de 5 anos no qual foram comparadas clinicamente infra-estruturas de titânio soldadas a laser com infra-estruturas de ouro. A perda de implantes foi maior nos pacientes com infra-estruturas de titânio que nos pacientes com infra-estruturas de ouro, mas esta diferença não foi estatisticamente significante. Muitas fraturas de infra-estruturas de titânio ocorreram comparadas com as infra-estruturas de ouro, nenhuma diferença estatisticamente significante também foi encontrada. A fratura dos dentes artificiais ocorreu mais nos pacientes com infra-estruturas de titânio. O fato de que os técnicos não estavam familiarizados com a fabricação de próteses fixas de titânio pode ter contribuído para estas complicações.

A falta de estudos longitudinais de pacientes com infra-estruturas de titânio soldadas a laser levou ÖRTORP; LINDEN; JEMT ${ }^{57}$, em 1999, relatarem 0 desempenho clínico de 5 anos de próteses implantosuportadas soldadas a laser. Os autores compararam os resultados deste tratamento com um grupo controle. Um total de 824 pacientes edêntulos foram tratados com próteses fixas suportadas por implantes na mandíbula. Destes pacientes, 51 receberam próteses com cilindros de titânio soldados com uma barra de titânio. O segundo grupo, 104 pacientes, receberam infra-estruturas de titânio sendo que os componentes de titânio eram separados entre si e colocados nas réplicas dos implantes, sobre os quais foram soldados com uma barra de titânio intacta. O grupo controle consistiu de 53 pacientes com próteses fixas fundidas em ouro. Os 
resultados deste estudo mostraram que o índice de sucesso foi de $95,9 \%$ e 99,7\% para próteses com infra-estruturas de titânio e implantes, respectivamente. O índice de sucesso do grupo controle foi de $100 \%$ e $99,6 \%$, respectivamente. As complicações mais comuns para as infraestruturas de titânio foi a fratura da infra-estrutura (10\%). A fundição das infra-estruturas tiveram o mais alto índice de sucesso, os resultados do tratamento com infra-estruturas de titânio estavam de acordo com os resultados do grupo controle. As infra-estruturas de titânio soldadas a laser mostraram ser uma alternativa viável para fundições convencionais nas mandíbulas edêntulas.

Com o objetivo de encontrar uma adaptação precisa das próteses sobre implantes, WEE; AQUILINO; SCHNEIDER ${ }^{79}$, em 1999, realizaram uma revisão de literatura. A maioria dos artigos revisados eram clínicos ou técnicos e mostravam estratégias para melhorar a adaptação das próteses sobre implantes. Os autores observaram que muitos métodos têm sido cientificamente comprovados para isto acontecer. A maioria das estratégias testadas resultaria em uma pequena interface da infra-estrutura com o intermediário do implante. Muitos fatores impedem que o conceito de "adaptação passiva" possa ser encontrado nas próteses sobre implantes, mesmo com o uso de estratégias avançadas.

Preocupados em saber a melhor maneira para verificar clinicamente a adaptação das próteses sobre implantes, KAN et al $^{42}$, em 1999, realizaram um trabalho. Vários métodos clínicos que têm sido sugeridos para avaliar a adaptação das infra-estruturas dos implantes foram revisados. Os níveis sugeridos de adaptação passiva são empíricos. Muitas técnicas têm sido sugeridas para avaliar a interface próteseimplante, mas nenhuma individualmente oferece um resultado objetivo. Os autores sugerem que os clínicos utilizem uma combinação dos vários métodos para minimizar a desadaptação. 
PROPOSIÇÃ O 


\section{PROPOSIÇ $\tilde{A} O$}

Com 0 intuito de determinarmos padrões que possibilitem análise comparativa para avaliar a adaptação, nas condições de comparação de componentes protéticos para implante do tipo esteticone, antes e após soldagem, propomo-nos avaliar:

3.1- a adaptação da interface intermediários esteticone/componentes de plástico fundidos com titânio e liga de cobalto-cromo.

3.2- a adaptação da interface intermediários esteticone/componentes de plástico fundidos em monobloco (peça única) e após soldagem a laser.

3.3- a adaptação individual nos três cilindros, dos intermediários/componentes de plástico fundidos em titânio e cobaltocromo, antes e após soldagem a laser

3.4- as possíveis interações entre as três condições estudadas (Material, Técnica e Cilindros). 
MATERIAL E MÉTODOS 


\section{MATERIAL E MÉTODOS}

\section{1 - CONFECÇÃO DO MODELO MESTRE}

Para obtenção do modelo mestre foi confeccionada uma base em resina acrílica autopolimerizável incolor (Artigos Odontológicos Clássico LTDA, São Paulo), de forma retangular com as seguintes características $4 \mathrm{~cm}$ de comprimento, $1 \mathrm{~cm}$ de largura e $1,5 \mathrm{~cm}$ de altura. Com o auxílio de um delineador (BIO-ART-Indústria e Comércio de Máquinas e Aparelhos para uso em Odontologia- São Carlos, São Paulo, Brasil), foram realizadas perfurações no acrílico, de forma previamente estabelecida, para o posicionamento dos implantes. Desta forma realizou-se 3 perfurações, sendo uma no centro da base de resina e as outras duas eqüidistantes nas extremidades da base, com dimensões $3 \mathrm{~cm} \times 1,5 \mathrm{~cm} \times 1,5 \mathrm{~cm}$ como mostra a Figura 4.1. Fixou-se com resina acrílica incolor (Artigos Odontológicos Clássico LTDA, São Paulo) 3 implantes, com hexágono externo, do sistema Conexão (Conexão Sistemas de Prótese - São Paulo - SP - Brasil) sendo estes de $10 \mathrm{~mm}$ de altura $x$ $3,75 \mathrm{~mm}$ de diâmetro, com base de assentamento 4.1 , tendo-se 0 cuidado de manter exposto os hexágonos $e$ as bases de assentamento. Sobre cada implante foram acomodados e parafusados intermediários do tipo Esteticone 22CNB-A, com cinta de $3 \mathrm{~mm}$, do sistema Conexão, com um torque mecânico de $20 \mathrm{Ncm}$, executado pelo controlador de torque (Nobelbiocare - Torque Controller ${ }^{\mathrm{TM}}$ Gotemburgo, Suécia).

Para a realização da análise estatística e verificação da possibilidade de uma maior interface nos implantes da extremidade, os implantes foram denominados de cilindros 1,2 e 3 .

Foi realizada uma caixa metálica, com superfícies paralelas, em latão, no qual a base de resina ficou contida e assentada. Os 
serviços de torneamento foram prestados pelo SENAI - Unidade Bauru - SP) (Figura 4.1). A confecção da caixa metálica tinha a princípio dois objetivos, primeiro evitar possíveis alterações na base de resina acrílica durante o experimento e, segundo ter um encaixe perfeito com a base metálica em forma de $L$ e possibilitar a leitura óptica das interfaces.

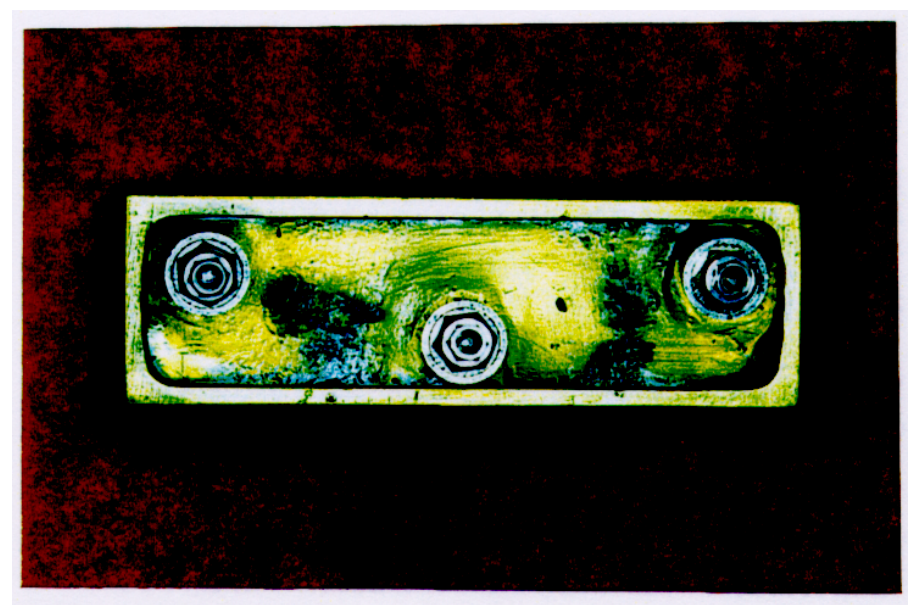

Figura 4.1- Modelo mestre e o posicionamento dos implantes.

\section{2 - ENCERAMENTO DOS CORPOS DE PROVA}

Para confecção dos corpos de prova foram utilizados 30 cilindros torneados em plástico 105CNB e 15 barras cilíndricas, também plásticas, para interligação dos cilindros (Conexão Sistemas de Prótese - São Paulo - SP - Brasil). Os cilindros de plástico do tipo Esteticone apresentam duas margens, sendo uma mais cervical e outra mais oclusal, determinadas pelo procedimento eletrônico de fabricação. Dessa forma, uma fina camada de cera para incrustações (Kota - Indústria e Comércio - São Paulo - SP), foi aplicada sobre os cilindros não invadindo suas margens demarcadas previamente (Figuras 4.2 e 4.3 ). 


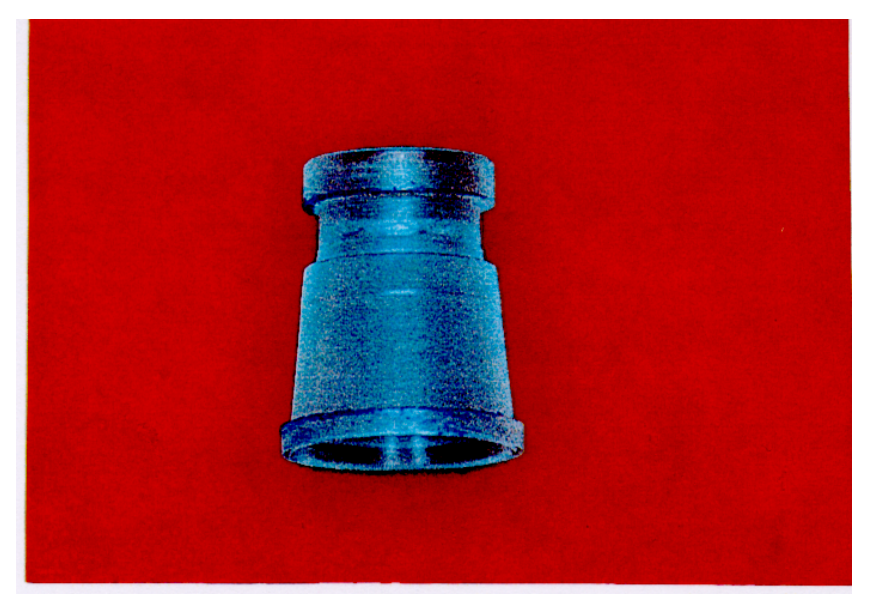

Figura 4.2 - Cilindro de plástico demarcado para padronização do enceramento.

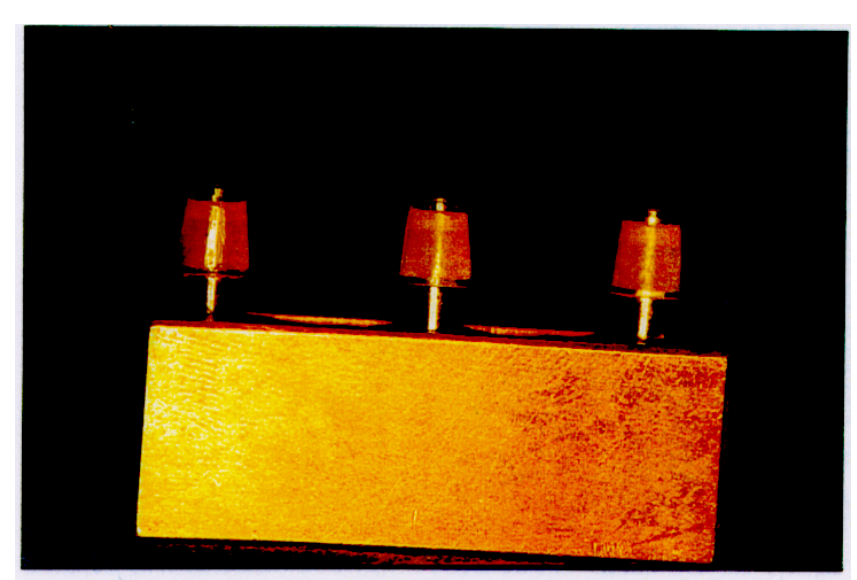

Figura 4.3 - Cilindros de plástico encerados.

Os cilindros de plástico, agora encerados, foram posicionados nos intermediários com um parafuso de trabalho protético 118CNB (Conexão Sistemas de Prótese - São Paulo - SP - Brasil). Uma barra cilíndrica de 1,8mm da mesma empresa (Conexão Sistemas de Prótese - São Paulo - SP Brasil) foi recortada e, aplicando-se cera (Kota - Indústria e Comércio - 
São Paulo - SP) em suas extremidades, uniu o cilindro central aos outros dois lateralmente. As barras foram posicionadas na metade da altura de cada cilindro, finalizando assim o enceramento do corpo de prova (Figura 4.4).

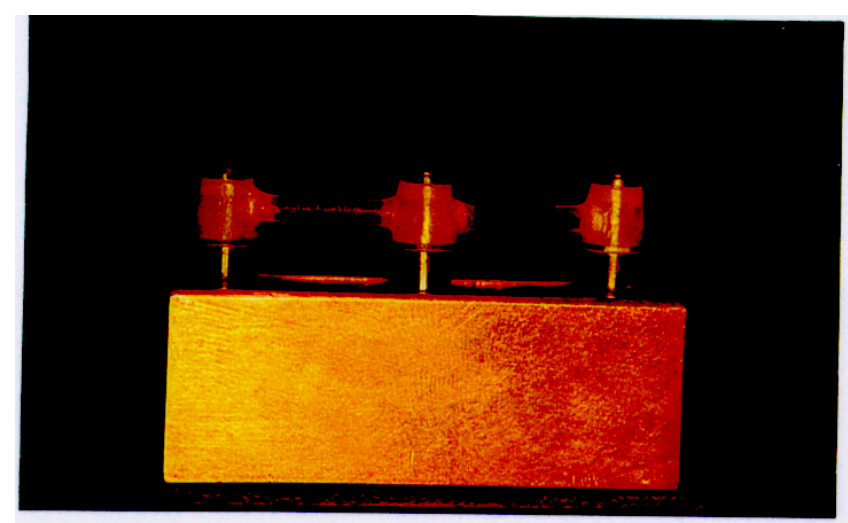

Figura 4.4 - Corpo de prova encerado.

Foram realizados 10 corpos de prova, sendo que destes 5 foram fundidos com uma liga de cobalto-cromo (Rexillium ${ }^{\circledR}$ N.B.F. - Jeneric ${ }^{\circledR} /$ Pentron ${ }^{\circledR}$ Incorporated) e os outros 5 fundidos em titânio (rematitan ${ }^{\circledR}$ Dentaurum Pforzheim- Alemanha).

A partir daí, estes corpos de prova foram definidos como estruturas metálicas.

\section{3 - OBTENÇÃO DAS ESTRUTURAS METÁLICAS EM LIGA DE COBALTO-CROMO}

\subsection{1 - INCLUSÃO}

Em uma base formadora de cadinho, foi adaptada uma barra do tipo "Speedbar" (ESBG 100 - Phoenix Tech. Inc.) que é um sprue do tipo indireto, indicado para casos em que vários elementos serão incluídos em 
um mesmo anel. Foram incluídos, em cada anel, 2 corpos de prova. Estes, foram posicionados no sprue através de um fio de cera de $2 \mathrm{~mm}$ de espessura. Aplicou-se um agente redutor de tensão superficial (Anti-bolhas - Kota - Indústria e Comércio - São Paulo - SP), em toda a superfície do padrão em cera, retirando-se os excessos com jatos de ar. Após estas etapas um anel de silicone, com capacidade para $150 \mathrm{gr}$ de revestimento, foi adaptado à base formadora de cadinho (Figura 4.5).

O revestimento utilizado foi do tipo aglutinado por fosfato de micropartículas (Talladium Micro-Fine 1700 - Odontológica), o qual foi proporcionado de acordo com as especificações do fabricante $(16 \mathrm{ml}$ de líquido específico $+6 \mathrm{ml}$ de água para um envelope de $90 \mathrm{gr}$ ). A espatulação do revestimento foi realizada de acordo com a técnica do próprio fabricante, que consistiu em incorporar o pó ao líquido, espatular por aproximadamente 10segundos e levar à espatulação mecânica (Vacuum Power Mixer Plus - Whip Mix Corporation - USA), por 40 segundos.

Os corpos de prova foram pincelados com o revestimento na porção interna de cada cilindro e, então, preencheu-se por completo o anel de silicone com o revestimento ainda sob vibração.

A inclusão foi realizada utilizando a técnica manual, com auxílio de vibração mecânica. Aguardou-se o tempo de presa do revestimento de acordo com as especificações da empresa (25 minutos, a uma temperatura de $22^{\circ} \mathrm{C}$ ), antes de prosseguir aos passos seguintes. 


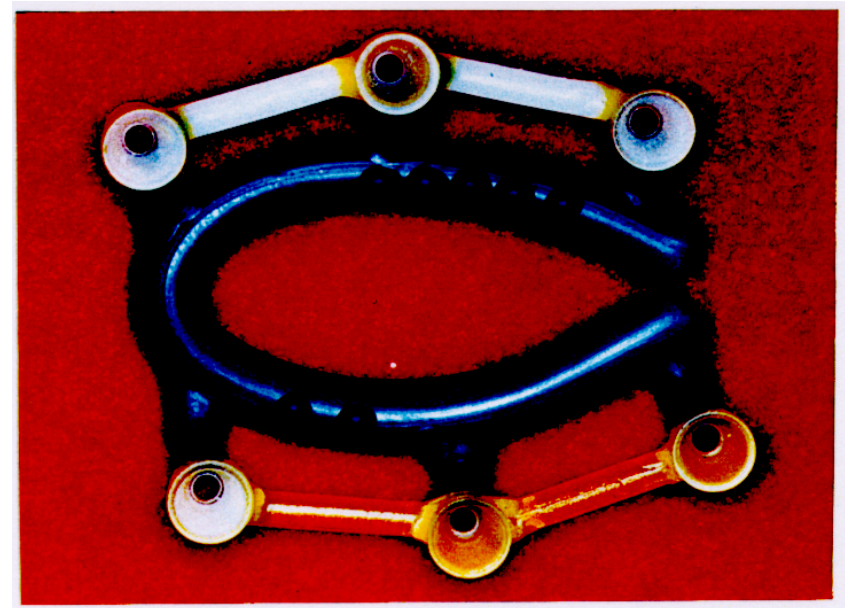

Figura 4.5 -Corpos de prova posicionados na barra de cera.

\subsection{2 - FUNDIÇÃO}

Após a remoção da base formadora de cadinho e do anel de silicone, o conjunto obtido na inclusão foi colocado no interior do forno (Radiance - Jelrus - USA), na posição inclinada, a uma temperatura de $870^{\circ} \mathrm{C}$ como exigida pela liga de cobalto-cromo Rexillium N.B.F. (Jeneric ${ }^{\circledR} /$ Pentron $^{\circledR}$ Incorporated), para eliminação da cera e plástico.

O cadinho cerâmico, previamente aquecido, foi posicionado no braço da centrífuga para fundição que foi ativada, sempre com a mesma quantidade de voltas. A liga (Rexillium ${ }^{\circledR}$ N.B.F. Jeneric $^{\circledR} /$ Pentron $^{\circledR}$ Incorporated) foi colocada no local apropriado e fundida de forma uniforme e gradual, através de um maçarico (RPM 247.5 - Swiss Made) com proporções adequadas de propano/oxigênio. A obtenção do aspecto da liga em seu ponto de liquefação (1426 ํ) determinou o momento de liberar a trava da centrífuga, para que o metal fosse injetado no interior do molde (Figura 4.6) 


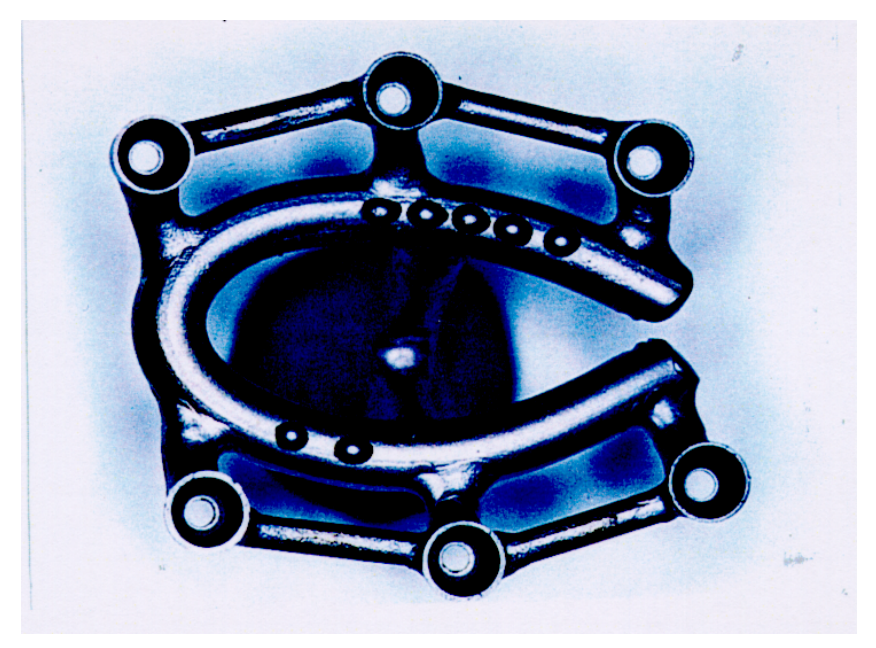

Figura 4.6 - Estruturas metálicas obtidas em liga de cobalto-cromo.

\section{4 - OBTENÇÃO DAS ESTRUTURAS METÁLICAS EM TITÂNIO}

\subsection{1 - INCLUSÃO}

Em uma base de forma cônica tamanho 3 (Dentaurum, Pforzheim, Alemanha, ref. 106-850-00), foi adaptado um canal principal de cera em forma de " $T$ " com diâmetro de $4 \mathrm{~mm}$. Os padrões de cera foram posicionados horizontalmente, com uma distância de $10 \mathrm{~mm}$ do bordo do anel. Foram incluídos, em cada anel, 2 corpos de prova. Com objetivo de se conseguir uma melhor umidade, os padrões de cera foram pulverizados com o redutor de tensões Lubrofilm ${ }^{\circledR}$ (Dentaurum, Pforzheim, Alemanha) e a secagem foi realizada com jatos de ar. Um cilindro com anel metálico de tamanho 3 do mesmo fabricante (ref.106-801-00) foi assentado à base cônica (Figura 4.7). A união do cone com o anel metálico deve ser precisa e limpa para se conseguir uma fluidez adequada do metal. Uma tela de amianto seca ( Kera-Vlies ${ }^{\circledR}$ - Dentaurum) foi adaptada à superfície interna do anel metálico, deixando os bordos superior e inferior do cilindro em contato direto com o revestimento. 
O revestimento utilizado foi o rematitan ${ }^{\circledR}$ ultra ${ }^{\circledR}$ ( Dentaurum, Pforzheim, Alemanha) que se distingue por sua reação particularmente baixa com o titânio puro permitindo um melhor resultado de fundição . Proporcionou-se de acordo com as especificações do fabricante $(35 \mathrm{ml}$ de líquido $+250 \mathrm{gr}$ de pó). A espatulação do revestimento foi realizada de acordo com a técnica do próprio fabricante., que consistiu em incorporar o pó ao líquido, espatular por aproximadamente 10segundos e levar à espatulação mecânica (Vacuum Power Mixer Plus - Whip Mix Corporation - USA), por 60 segundos.

Os corpos de prova foram pincelados com o revestimento na porção interna de cada cilindro de forma semelhante ao descrito anteriormente e, então, preencheu-se por completo o anel de fundição com o revestimento.

A inclusão foi realizada utilizando a técnica manual, com auxílio de vibração mecânica. Os padrões de cera ficaram cobertos por uma pequena quantidade de revestimento ( $5 \mathrm{~mm}$ aproximadamente). Aguardou-se 0 tempo de presa do revestimento de acordo com as especificações da empresa ( 2 horas, a uma temperatura de $22^{\circ} \mathrm{C}$ ), antes de prosseguir aos passos seguintes.

O cilindro foi , então, recortado e estes foram colocados no forno frio, com a abertura voltada para baixo. $O$ forno foi aquecido gradativamente. A temperatura foi elevada de 3 a $5^{\circ} \mathrm{C} /$ minuto até a temperatura de $250^{\circ} \mathrm{C}$ e então aguardou-se 20 minutos. A partir daí, a temperatura foi elevada $5^{\circ} \mathrm{C}$ a cada minuto, até atingir $880^{\circ} \mathrm{C}$ e o tempo de espera foi de 40 minutos. Uma vez alcançada a temperatura final, procedeu-se ao resfriamento até a temperatura de $430^{\circ} \mathrm{C}$ aguardando-se 30 minutos. O tempo total de resfriamento foi de 5 horas. A expansão do revestimento foi controlada através da temperatura do forno. 


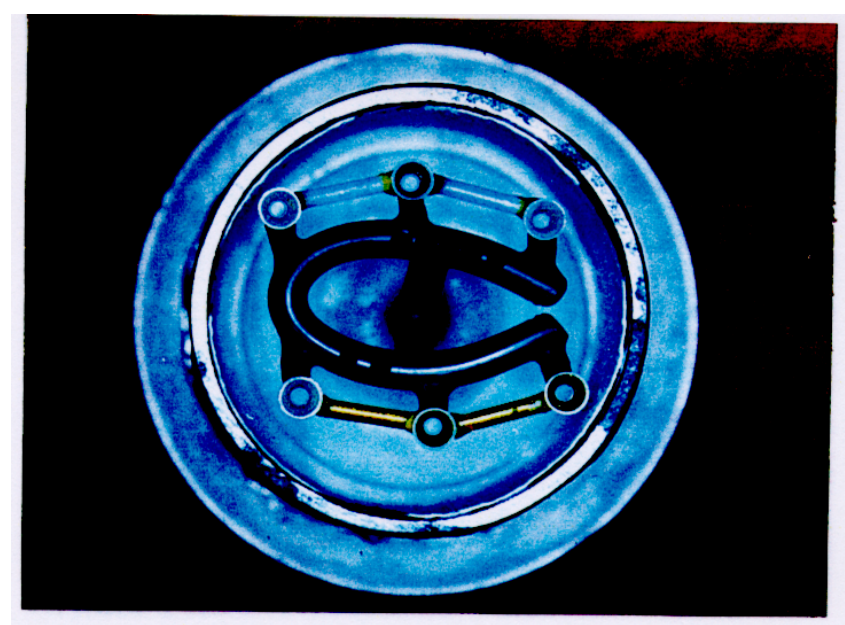

Figura 4.7 - Vista superior do anel metálico para fundição do titânio

\subsection{2 - FUNDIÇÃO}

A fundição do titânio foi realizada na máquina de fundição rematitan ${ }^{\circledR}$ autocast ( Dentaurum, Pforzheim, Alemanha). Neste sistema, o técnico é guiado por centenas de informações que aparecem no visor e o processo de fundição, propriamente dito, desenvolve-se de forma totalmente automática (Figura 4.8).

O rematitan ${ }^{\circledR}$ autocast é um sistema fechado de duas câmaras, unidas entre si, que permite a fundição por arco voltaico de corrente contínua, com eletrodo de wolframio em uma câmara à vácuo, inundada de argônio. Como cadinho utilizou-se um "funil” de cobre.

As fundições do titânio foram realizadas no Laboratório Vaiazi, em São Paulo. 


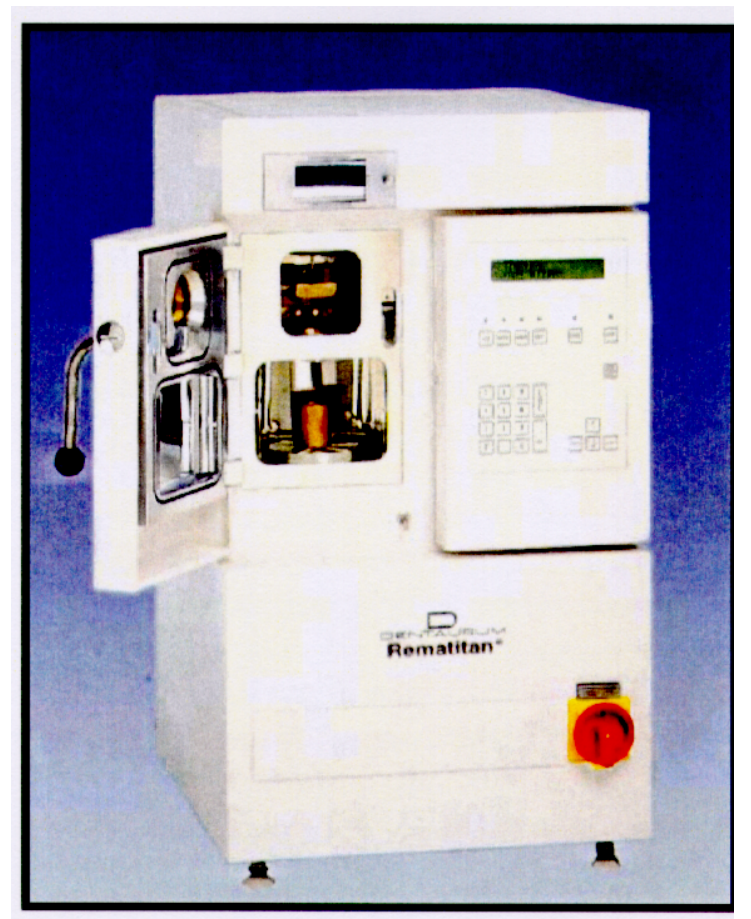

Figura 4.8 - Aparelho para fundição de titânio - rematitan ${ }^{\circledR}$

Para a fundição das estruturas, foi utilizado o titânio puro que se apresenta em forma de "lingotes cilíndricos", com um grau de pureza, segundo DIN 17850, no mínimo de 99,5\% de titânio. Cada lingote estava demarcado com o nome rematitan ${ }^{\circledR}$ ( Dentaurum), grau de pureza e número de lote (Figura 4.9).

O revestimento foi colocado na câmara inferior e fixado. Os lingotes de titânio rematitan ${ }^{\circledR}$ foram colocados sobre o "funil" de cobre e o técnico programou o sistema de acordo com a quantidade de meta utilizado para cada ciclo de fundição (rematitan ${ }^{\circledR}$ - 22 gramas). A partir daí, o sistema encarregou-se de vigiar e controlar as condições de pressão na câmara de fundição

O processo de fundição ocorreu devido ao vácuo existente na câmara inferior e a pressão do argônio na câmara superior. Uma vez transcorrido o tempo de fusão, o titânio fluiu para baixo no cilindro de 
revestimento passando pelo cadinho sem sofrer qualquer reação com 0 mesmo. (Figura 4.10)

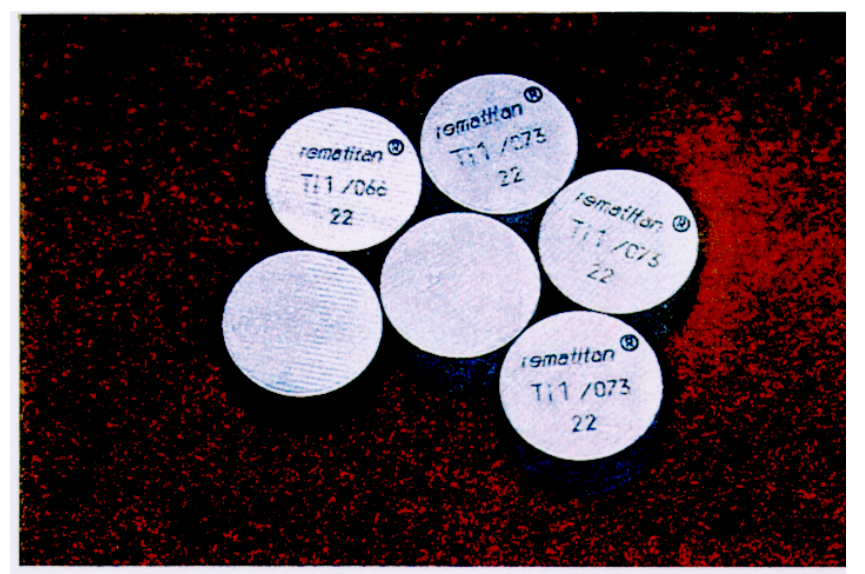

Figura 4.9 - Lingotes de titânio

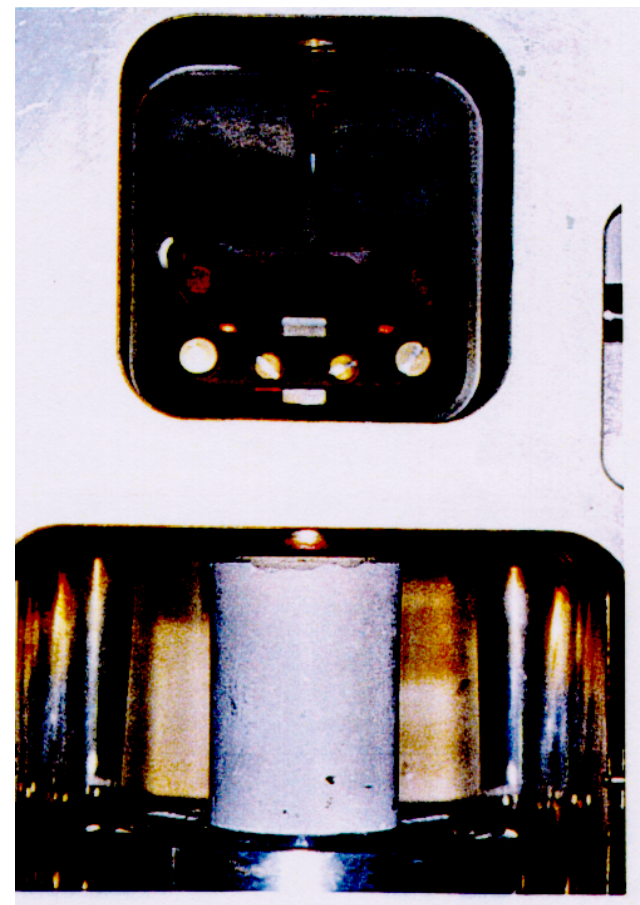

Figura 4.10 - Visão interna do aparelho de fundição de titânio - rematitan ${ }^{\circledR}$ 


\section{5 - ACABAMENTO DAS ESTRUTURAS METÁLICAS}

As desinclusões foram realizadas após o resfriamento, com suaves cortes laterais do anel de revestimento e foi aplicado um jato abrasivo de óxido de esferas de vidro, com partículas de $100 \mu \mathrm{m}$ e pressão $60 \mathrm{Lb} / \mathrm{pol}^{2}$, para remover os restos deste. Os condutos de alimentação foram seccionados e a superfícies internas dos cilindros avaliadas com o auxílio de uma lupa com aumento de 4 vezes. Caso houvesse bolhas positivas, as mesmas eram cuidadosamente removidas, como se faz na prática laboratorial diária. Não houve, no entanto, intenção de se fazer usinagem interna, para obter melhor adaptação, para que os resultados não fossem alterados.

As estruturas metálicas receberam acabamento com suas bordas protegidas por um dispositivo metálico apropriado, utilizando-se discos de óxido de alumínio de granulação regular (Dentorium Internacional Incorporated., N.Y., USA).

Para as estruturas metálicas de titânio, com intuito de detectar possíveis defeitos decorrentes do procedimento de fundição, foram realizadas tomadas radiográficas no aparelho de Raio X GE $100 \mathrm{Kv}$ (General Eletric) com voltagem de 10MA, tempo de exposição de $5 \mathrm{mseg}$ e distância foco/filme de $15 \mathrm{~cm}$, utilizando-se uma película periapical (Kodak - Ektaspeed plus - EP-21P - Size 2). A presença de porosidades no interior das fundições quando detectadas determinaram a exclusão destas peças.

4.6 - ANÁLISE DAS MEDIDAS VERTICAIS DAS INTERFACES INTERMEDIÁRIO/COMPONENTE PROTÉTICO APÓS AS FUNDIÇÕES EM MONOBLOCO

Para analisar e medir as interfaces foi utilizado um microscópio comparador (Mitutoyo Mfg. Co, LTDA, Japan) modelo B I 5, código 176, com aumento de 30 vezes (ocular de 15 vezes e objetiva de 2 vezes) e cabeçotes micrométricos 43627 e 33339 , com mostrador digital embutido e 
medidas a cada $5 \mathrm{~mm}$, de propriedade do laboratório da Disciplina de Materiais Dentários da Faculdade de odontologia de Bauru - USP - SP (Figura 4.11)

As estruturas metálicas foram encaixadas e posicionadas no modelo mestre e, por meio de parafusos de titânio com hexágono 11 CNB (Conexão Sistemas de Prótese - São Paulo - SP - Brasil), foram apertadas com um torque de $10 \mathrm{Ncm}$, executado por um controlador de torque mecânico (Nobelbiocare - Torque Controller ${ }^{\mathrm{TM}}$ Gotemburgo, Suécia).

A superfície plana de assentamento da base foi fixada à base do microscópio, e o modelo mestre com as estruturas metálicas foram posicionados para as leituras (Figura 4.12). O cabeçote micrométrico corria da superfície do intermediário até a linha que consistia na base do cilindro protético, obtendo-se dois valores. A diferença entre esses valores era 0 valor anotado para aquela interface. Como os cabeçotes possuem os mostradores calibrados a cada $5 \mu \mathrm{m}$, convencionou-se que medidas que ficassem entre dois riscos verticais da escala receberiam aproximação para o valor maior.

Foram realizadas 4 medições ao redor de cada cilindro da estrutura metálica sendo que cada ponto foi lido por 3 vezes. Um total de 12 leituras foram realizadas em cada cilindro da estrutura metálica. 


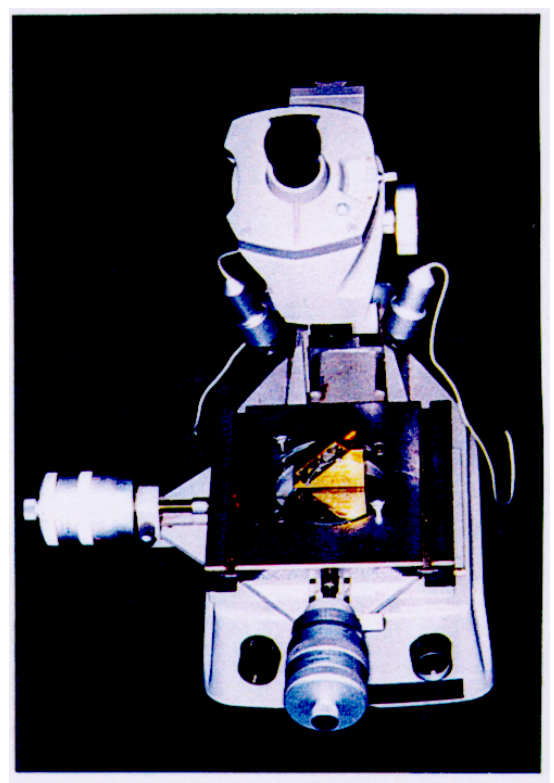

Figura 4.11 -Microscópio óptico comparador utilizado

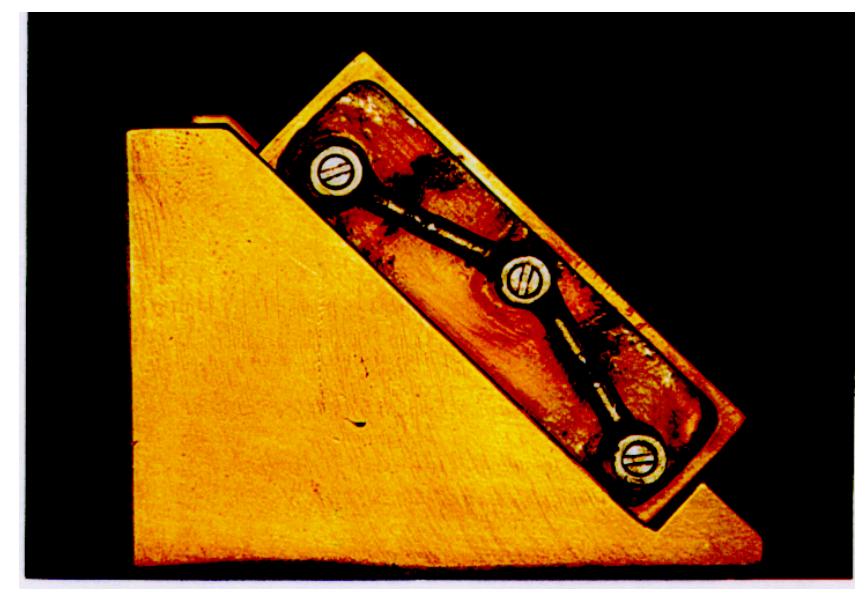

Figura 4.12 - Modelo mestre posicionado para leitura - visão frontal.

Com a intenção de se realizar essas medições no microscópio, sem que houvesse sobreposição dos cilindros, quando na leitura das superfícies mesiais dos dois cilindros da periferia, foi confeccionado um 
dispositivo de base triangular em latão em forma de L. A usinagem da base foi feita no SENAI (SENAI - Unidade Bauru - SP), com as seguintes características: $4 \mathrm{~cm}$ de comprimento, $3,5 \mathrm{~cm}$ de altura com uma inclinação de $45^{\circ}$ em relação à base.

Com a utilização deste dispositivo, o modelo mestre ficou posicionado sobre a rampa, possibilitando a leitura das superfícies mesiovestibular, disto-vestibular, mesio-lingual e disto-lingual de cada cilindro metálico. Por meio de pequenas marcações, confecionadas com uma lâmina de bisturi, pôde-se realizar as leituras sempre na mesma condição.

\section{7 - SOLDAGEM A LASER}

As estruturas metálicas foram posicionadas sobre o modelo mestre e uma marcação foi realizada na metade da extensão de cada barra, onde procedeu-se o seccionamento destas. Com um disco de Carborundum ultra fino ( ref. 9500.900.220 - GEBR. BRASSELER Gmbh \& Co. KG, Lemgo, República Federal da Alemanha), seccionou-se as barras e os componentes agora separados foram parafusados com um torque mecânico de $10 \mathrm{Ncm}$, utilizando o mesmo aparelho (Figura 4.13). Este conjunto, foi levado para o interior da máquina de soldagem a laser (DL2002S - Laser - Dentaurum, Pforzheim, Alemanha) (Figura 4.14). Segurando com as mãos e, olhando pela ocular do aparelho, o técnico controla com os pés a quantidade de pulsos emitidos para realização da soldagem. Para soldar as estruturas de titânio, a máquina foi programada a $300 \mathrm{~V} / 10 \mathrm{mseg}$, numa freqüência de focus 0 . Para soldar as estruturas de cobalto-cromo, a máquina foi programada a $300 \mathrm{~V} / 12 \mathrm{mseg}$, numa freqüência focus 0 (Figura 4.15).

Após a soldagem a laser procedeu-se às novas leituras, utilizando os mesmos critérios das leituras iniciais. Os dados foram coletados e organizados para análise.

Para realização da análise estatística utilizou-se o teste de análise de variância a três critérios (ANOVA). 


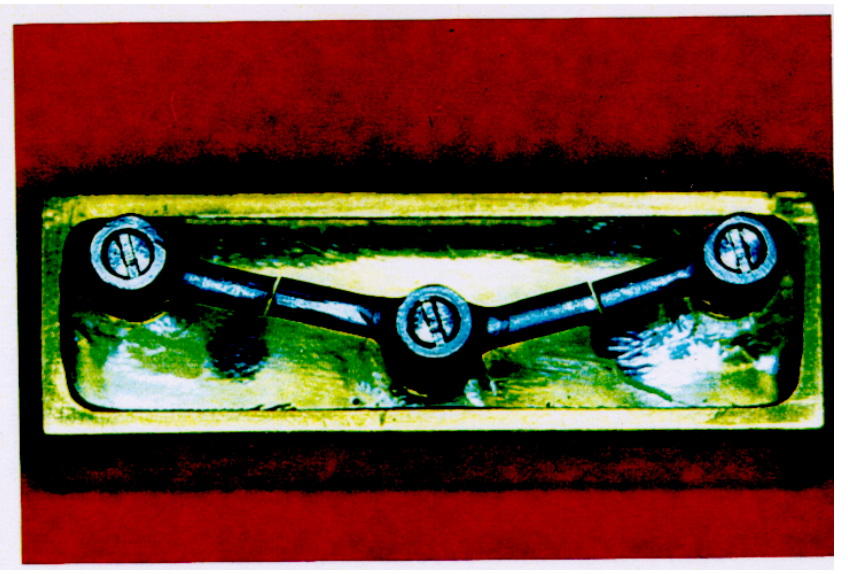

Figura 4.13 - Estrutura metálica seccionada.

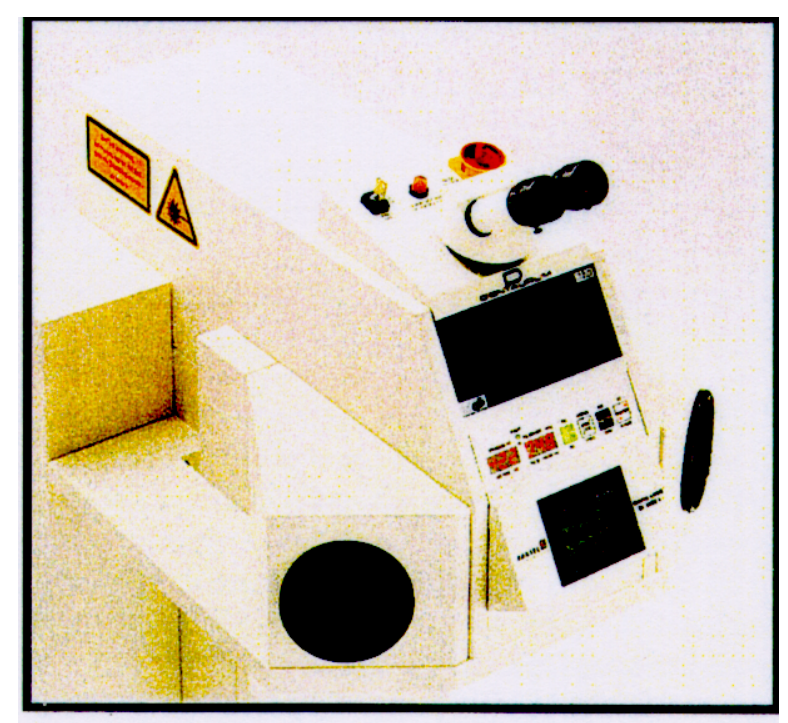

Figura 4.14 - Aparelho de solda a laser. 


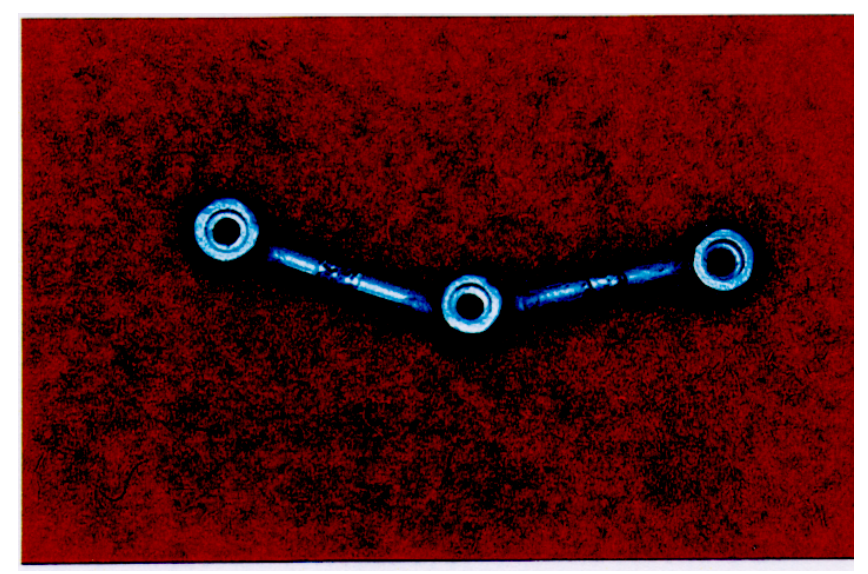

Figura 4.15 - Estrutura metálica após soldagem. 
RESULTADOS 


\section{RESULTADOS}

O objetivo deste estudo foi avaliar, por meio de inspeção microscópica, possíveis alterações verticais nas interfaces dos componentes protéticos/intermediários em função do emprego de dois diferentes materiais, rotineiramente utilizados para confecção de estruturas protéticas, antes a após soldagem, para passivação dos componentes.

Para tanto foram realizadas comparações entre os dois materiais $(\mathrm{Ti}$ e Co- $\mathrm{Cr}$ ) e duas técnicas de confecção de estruturas protéticas e a interação das mesmas. A Tabela 1 apresenta os valores médios em micrometros da interface componente protético/intermediário, obtidos nas estruturas metálicas confeccionadas a partir de cilindros usinados em plástico, fundidos em monobloco com a liga de titânio.

TABELA 1 - Valores médios da interface componente protético/intermediário $(\mu \mathrm{m})$, obtidos a partir da fundição em monobloco de cilindros usinados em plástico, com titânio.

\begin{tabular}{c|c|c|c|c}
\hline $\begin{array}{c}\text { Corpo de } \\
\text { prova }\end{array}$ & Material & Cilindro 1 & Cilindro 2 & Cilindro 3 \\
\hline 1 & $\mathrm{Ti}$ & 21,665 & 23,745 & 16,665 \\
\hline 2 & $\mathrm{Ti}$ & 25,415 & 20,415 & 34,997 \\
\hline 3 & $\mathrm{Ti}$ & 20,830 & 19,580 & 26,245 \\
\hline 4 & $\mathrm{Ti}$ & 31,662 & 24,580 & 27,497 \\
\hline 5 & $\mathrm{Ti}$ & 25,412 & 25,832 & 21,247 \\
\hline
\end{tabular}


A Tabela 2 apresenta os valores médios em micrometros da interface componente protético/intermediário, obtidos nas estruturas metálicas confeccionadas a partir de cilindros usinados em plástico, fundidos em monobloco com a liga de cobalto-cromo.

TABELA 2 - Valores médios da interface componente protético/intermediário $(\mu \mathrm{m})$, obtidos a partir da fundição em monobloco de cilindros usinados em plástico, com liga de cobalto-cromo.

\begin{tabular}{c|c|c|c|c}
\hline $\begin{array}{c}\text { Corpo de } \\
\text { prova }\end{array}$ & Material & Cilindro 1 & Cilindro 2 & Cilindro 3 \\
\hline 1 & Co-Cr & 23,745 & 24,997 & 25,415 \\
\hline 2 & Co-Cr & 42,915 & 22,497 & 29,577 \\
\hline 3 & Co-Cr & 30,000 & 26,665 & 27,915 \\
\hline 4 & Co-Cr & 25,415 & 27,497 & 33,332 \\
\hline 5 & Co-Cr & 27,082 & 32,082 & 20,000 \\
\hline
\end{tabular}

A Tabela 3 apresenta os valores médios em micrometros da interface componente protético/intermediário, obtidos nas estruturas metálicas confeccionadas a partir de cilindros usinados em plástico, fundidos em titânio e soldados a laser. 
TABELA 3 - Valores médios da interface componente protético/intermediário $(\mu \mathrm{m})$, obtidos a partir da soldagem a laser de cilindros usinados em plástico, fundidos em titânio.

\begin{tabular}{c|c|c|c|c}
\hline $\begin{array}{c}\text { Corpo de } \\
\text { prova }\end{array}$ & Material & Cilindro 1 & Cilindro 2 & Cilindro 3 \\
\hline 1 & $\mathrm{Ti}$ & 22,915 & 16,665 & 13,750 \\
\hline 2 & $\mathrm{Ti}$ & 22,500 & 18,332 & 19,165 \\
\hline 3 & $\mathrm{Ti}$ & 10,000 & 15,415 & 19,582 \\
\hline 4 & $\mathrm{Ti}$ & 26,250 & 17,082 & 15,415 \\
\hline 5 & $\mathrm{Ti}$ & 13,750 & 27,500 & 13,750 \\
\hline
\end{tabular}

A Tabela 4 apresenta os valores médios em micrometros da interface componente protético/intermediário, obtidos nas estruturas metálicas confeccionadas a partir de cilindros usinados em plástico, fundidos com a liga de cobalto-cromo e soldados a laser.

TABELA 4 - Valores médios da interface componente protético/intermediário $(\mu \mathrm{m})$, obtidos a partir da soldagem a laser de cilindros usinados em plástico, fundidos com liga de cobalto-cromo.

\begin{tabular}{c|c|c|c|c}
\hline $\begin{array}{c}\text { Corpo de } \\
\text { prova }\end{array}$ & Material & Cilindro 1 & Cilindro 2 & Cilindro 3 \\
\hline 1 & Co-Cr & 22,915 & 27,497 & 19,997 \\
\hline 2 & Co-Cr & 31,665 & 22,080 & 14,997 \\
\hline 3 & Co-Cr & 23,747 & 21,665 & 22,912 \\
\hline 4 & Co-Cr & 16,250 & 12,500 & 21,250 \\
\hline 5 & Co-Cr & 29,580 & 21,662 & 17,497 \\
\hline
\end{tabular}


A Tabela 5 apresenta a média dos valores e desvios padrões na interface componente protético/intermediário $(\mu \mathrm{m})$ em titânio e cobaltocromo, fundidas em monobloco e soldadas.

TABELA 5 - Valores médios e desvios padrão (dos diferentes grupos) da interface componente protético/intermediário $(\mu \mathrm{m})$, fundidos em titânio e cobalto-cromo, antes e após soldagem.

\begin{tabular}{c|l|c|c|c|c|c|c}
\hline \multirow{2}{*}{ Material } & \multirow{2}{*}{ Técnica } & \multicolumn{2}{c}{ Cilindro1 } & \multicolumn{2}{c}{ Cilindro 2 } & \multicolumn{2}{c}{ Cilindro 3 } \\
\cline { 3 - 8 } & & Média & DP & Média & DP & Média & DP \\
\hline Titânio & Monobloco & 24,997 & 4,278 & 22,830 & 2,706 & 25,330 & 6,905 \\
\hline Titânio & Pós solda & 19,083 & 6,867 & 18,999 & 4,865 & 16,332 & 2,862 \\
\hline Co-Cr & Monobloco & 29,831 & 7,669 & 26,748 & 3,541 & 27,248 & 4,969 \\
\hline Co-Cr & Pós solda & 24,831 & 6,077 & 21,081 & 5,396 & 19,331 & 3,126 \\
\hline
\end{tabular}

Os valores apresentados na Tabela 5 estão representados graficamente na Figura 5.1. 
Ti; monobloco

Co-Cr; monobloco

Ti; pós solda

Co-Cr; pós solda

$\mu \mathrm{m}$
30
20
10

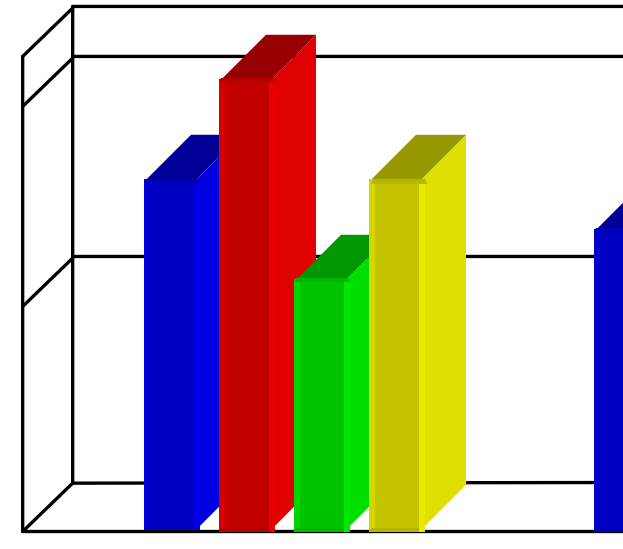

Cilindro 1
Cilindro 2 


\begin{tabular}{|c|c|c|c|c|c|c|}
\hline $\begin{array}{c}\text { Fonte de } \\
\text { variação }\end{array}$ & $\begin{array}{c}\text { gl } \\
\text { efeito }\end{array}$ & $\begin{array}{c}\text { Quadrado } \\
\text { Médio }\end{array}$ & $\begin{array}{c}\text { gl } \\
\text { erro }\end{array}$ & $\begin{array}{c}\text { Quadrado } \\
\text { Médio erro }\end{array}$ & $\mathbf{F}$ & $\mathbf{p}$ \\
\hline Material (1) & $1^{*}$ & $192,5755^{*}$ & $8^{*}$ & $25,320^{*}$ & $7,605^{*}$ & $0,024^{*}$ \\
\hline Técnica (2) & $1^{*}$ & $580,5624^{*}$ & $8^{*}$ & $17,003^{*}$ & $34,143^{*}$ & $0,000^{*}$ \\
\hline Cilindros (3) & 2 & 40,5853 & 16 & 45,967 & 0,882 & 0,432 \\
\hline Interação 1,3 & 2 & 11,3115 & 16 & 45,967 & 0,246 & 0,784 \\
\hline Interação 1,2 & 1 & 0,0106 & 8 & 17,003 & 0,000 & 0,980 \\
\hline Interação 2,3 & 2 & 19,3790 & 16 & 13,930 & 1,391 & 0,277 \\
\hline Interação 1,2,3 & 2 & 3,3529 & 16 & 13,930 & 0,240 & 0,788 \\
\hline
\end{tabular}

* diferença estatisticamente significante $(p<0,05)$

Figura 5.2 - Análise de variância a três critérios de classificação aplicada aos resultados dos diferentes grupos.

A análise de variância a três critérios, mostrou haver diferença estatisticamente significante nas adaptações entre os materiais e as técnicas, porém não houve diferença estatisticamente entre os cilindros e em interação entre as condições estudadas.

Através da Figura 5.3 podemos verificar que o titânio e a técnica de soldagem a laser apresentaram os melhores resultados no que diz respeito à adaptação. 


\begin{tabular}{|c|c|c|}
\hline \multicolumn{2}{|c|}{ Fonte de variação } & Média geral \\
\hline \multirow{2}{*}{ Material } & Titânio & $21,262 \mu \mathrm{m}$ \\
\cline { 2 - 3 } & Cobalto-Cromo & $24,845 \mu \mathrm{m}$ \\
\hline \multirow{2}{*}{ Técnica } & Monobloco & $26,164 \mu \mathrm{m}$ \\
\cline { 2 - 3 } & Pós solda & $19,943 \mu \mathrm{m}$ \\
\hline
\end{tabular}

Figura 5.3 - Média geral das ligas e técnicas estudadas. 
DISCUSSÃ 0 


\section{DISCUSS $\tilde{A} O$}

As próteses implanto-suportadas utilizadas na reabilitação de pacientes parcialmente, ou totalmente, desdentados é um procedimento clínico viável, com sucesso comprovado por diversos trabalhos ${ }^{1,34,35,41,81}$.

Algumas das maiores preocupações associadas com as próteses implanto-suportadas são: 1) as dificuldades técnicas em se obter uma adaptação precisa da infra-estrutura metálica quando os parafusos de fixação da prótese são apertados e, 2) o alto custo, quando ligas áureas são utilizadas para confecção da infra-estrutura. A soldagem a laser das infra-estruturas de titânio tem sido sugerida para solucionar ambos os problemas ${ }^{35,68}$.

O objetivo primário na fabricação de próteses implanto-suportadas é encontrar uma adaptação passiva entre o intermediário e a infra-estrutura protética. A importância desta passividade nas próteses sobre implantes tem sido discutida por muitos autores 20,24,26,35,38,39,41,49,52,55,61,65,66,70,78. Todavia, uma definição precisa do termo ainda não foi encontrada. Segundo CARLSSON; CARLSSON ${ }^{7}$, uma prótese com adaptação passiva significa que esta pode ser parafusada sem que tensões sejam geradas ${ }^{7}$. $\mathrm{JEMT}^{34}$, definiu adaptação passiva como o nível que não causaria qualquer complicação clínica e sugeriu que eventuais desadaptações fossem menores que $150 \mu \mathrm{m}$ para serem aceitáveis ${ }^{34}$.

Pobre adaptação ou alta concentração de estresse têm sido responsáveis por causar complicações biológicas e mecânicas, mas poucos estudos clínicos têm sido realizados para comprovar esta relação cientificamente. KALLUS; BESSING ${ }^{41}$ têm indicado a correlação entre pobre adaptação e instabilidade do parafuso de fixação da prótese mas, nestes casos, a interface foi provavelmente, maior que $30 \mu \mathrm{m}^{47}$. Os resultados obtidos, em nosso trabalho, determinaram as médias gerais das interfaces intermediários/componentes protéticos inferiores aos valores 
descritos por KALLUS; BESSING, como pode ser visualizado nas figuras 6.1 e 6.2 .

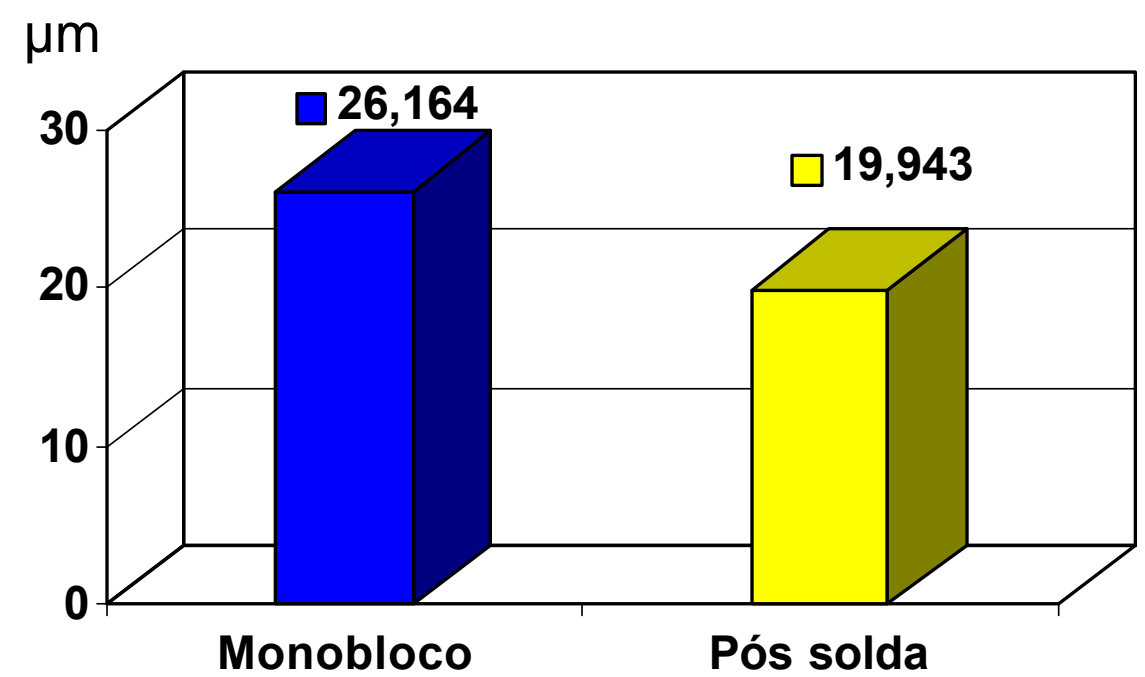

Figura 6.1 - Valores médios da interface componente protético/intermediário $(\mu \mathrm{m})$ fundidos em monobloco e após a soldagem.

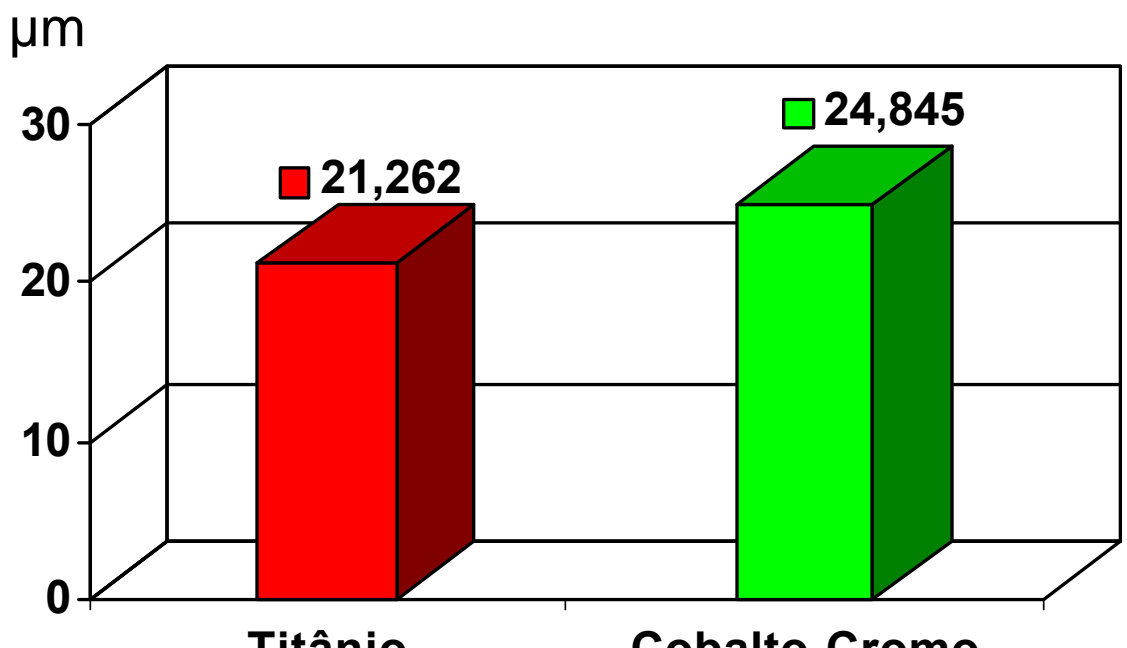

Figura 6.2 - Valores médios da interface componente protético/intermediário $(\mu \mathrm{m})$ fundidos em titânio e cobalto-cromo. 
Entretanto, uma interface intermediário/componente protético de $30 \mu \mathrm{m}$, dificilmente, é detectada na inspeção visual. Daí, a preocupação em definir métodos clínicos para avaliação desta condição. A avaliação clínica da adaptação tem sido subjetiva e descrita, geralmente, em termos de inspeção direta e sensação táctil com sonda exploradora ${ }^{42}$.

A mensuração do grau de adaptação pode ser realizada por outras técnicas como analisar a interface intermediário/componente protético ao microscópio, medindo a extensão vertical da interface ${ }^{43,49,70}$; aplicar testes de mobilidade através do aparelho "Periotest" ${ }^{49}$; transformações dos dados em informações tridimensionais através de programas computadorizados ${ }^{38}$; associação de imagem microscópica, fotografias e programas específicos de computador ${ }^{45}$; análises fotoelásticas ${ }^{55,78}$; avaliação da interface nos três eixos: horizontal, vertical e angular (combinação dos dois anteriores) $)^{7,24}$.

Embora para alguns autores ${ }^{7,24}$, a adaptação de uma prótese possa ser avaliada em três eixos, observa-se que a maioria dos trabalhos de adaptação consideram apenas o eixo vertical, sendo o termo "adaptação passiva", constantemente empregado na literatura como sinônimo de adaptação vertical ${ }^{32,43,70,78}$.

Apenas o eixo vertical foi considerado e analisado, neste trabalho, que pôde ser explicado pelo papel do parafuso protético, o componente do sistema que sofre falha com maior freqüência ${ }^{7,34,35,41,81}$.

Os componentes foram analisados após a fundição em monobloco das estruturas em dois diferentes materiais, antes e após a soldagem a laser, com o objetivo de verificar a tolerância do processo de fabricação descrito em outros trabalhos ${ }^{49}$.

Cada cilindro foi analisado e mensurado em quatro locais distintos, determinados pelo corpo de prova. Acredita-se que o cilindro ideal seria aquele que apresentasse menor interface quando em contato com o intermediário. Os dados foram submetidos a uma análise de variância a três critérios. Os resultados mostraram que existe diferença estatisticamente significante entre as técnicas (monobloco e soldagem a 
laser) submetidas à análise, assim como entre os materiais (titânio e cobalto-cromo). Foi encontrado diferença estatisticamente significante nas estruturas fundidas antes e após a soldagem a laser, confirmando o resultado de outros trabalhos que recomendam o seccionamento das peças para melhor adaptação $42,57,62,67$, para tanto seguimos o mesmo raciocínio, despertando-nos a curiosidade de qual tecnicamente teria o melhor comportamento. Fazendo uma analogia, as fundições em monobloco obtidas tiveram uma performance semelhante à descrita na literatura, sendo significativamente pior que após a soldagem a laser.

As fundições em monobloco têm sido usadas rotineiramente por alguns autores ${ }^{62,67,78}$, que também sugerem o seccionamento das peças em situações no qual uma análise intra-oral revela uma adaptação imprecisa ${ }^{67,78}$. SCHIEFFLEGER et $\mathrm{al}^{67}$, concluíram que 0 assentamento melhora, em aproximadamente $50 \%$, após o seccionamento das infraestruturas, sendo que, as peças de 3 elementos apresentaram uma menor distorção que as de 5 elementos ${ }^{67}$, dados aos quais o nosso trabalho se aproximou muito.

A construção das infra-estruturas em monobloco tem algumas vantagens como o tempo ganho na eliminação da soldagem e a avaliação da adaptação pode ser verificada imediatamente após a fundição. Um número de estudos têm relatado a precisão de próteses extensas fundidas em peça única. HULLING; $C_{L A R K}^{28}$, verificaram que fundições em peça única e a soldagem a laser são superiores à técnica de soldagem convencional $^{28}$.

A soldagem a laser das próteses fixas foi estudada, inicialmente, por GORDON; SMITH ${ }^{21}$, em 1970. Nenhuma união falhou sob condições normais de uso pelos pacientes e a economia de tempo é considerável. Foi verficado uma menor distorção da soldagem a laser quando comparada à técnica de soldagem convencional ${ }^{21}$, sendo estes resultados confirmados por outros trabalhos ${ }^{2,28}$. 
Cabe-se aqui, discutir o papel social das confecções protéticas, onde a tecnologia deva estar associada a serviço da grande parte da população. As ligas de cobalto-cromo têm ocupado um importante espaço na prática laboratorial pelo seu custo reduzido ${ }^{12,13,61,74}$. O cobalto-cromo é um material conveniente para infra-estruturas de próteses fixas implantosuportada, em casos onde não há problemas estéticos, preferivelmente, nos casos de mandíbula totalmente edêntula ${ }^{29}$. Vem tendo seu uso aumentado com o tempo e tem demonstrado características aceitáveis de adaptação ${ }^{11,15,29}$.

O titânio tem sua aplicabilidade e superioridade na capacidade de adaptação descrita em vários trabalhos ${ }^{4,26,37,39}$, tendo como desvantagem apenas a preocupação natural de técnicos e clínicos em adotar uma nova tecnologia ${ }^{64}$. Muitas vantagens se têm na utilização do titânio para construção de infra-estruturas implanto-suportadas ${ }^{3,10,25,27,63}$. Tais fatores justificaram a escolha deste para este trabalho.

Neste trabalho, utilizou-se cilindros de plástico para confecção da estrutura, que foram fundidos em materiais de baixo custo, visando o maior acesso da população para este tipo de tratamento.

A condição de três implantes foi utilizada para possibilitar a realização de overdentures, melhorando a estabilidade e a retenção destas $^{60}$. De acordo com PAVLATOS ${ }^{60}$, vários desenhos protéticos podem ser realizados nesta condição.

Após a fundição das estruturas metálicas, as peças foram polidas e colocadas sobre seus respectivos intermediários, com um torque mecânico de $10 \mathrm{Ncm}$, convencionado para que houvesse assentamento padronizado. Esse método foi utilizado por vários trabalhos ${ }^{34,65,70,78}$.

Foi realizado a análise entre os cilindros da estrutura metálica para verificar se o processo de fundição interfere no aumento da interface dos cilindros das extremidades. De acordo com SCHIEFFLEGER ${ }^{67}$, pode ocorrer o "empenamento" da peça devido a contração do material no processo de fundição ${ }^{67}$. 
Não foram observadas interações entre as variáveis acima descritas (Material, Técnica e Cilindro).

Desta forma, pode-se argumentar a viabilidade dos procedimentos técnicos empregados neste trabalho, deixando claro também que existem condições de reduzirmos o custo efetivo das próteses sobre implantes. Outros estudos devem ser realizados para testar novos materiais e tecnologias, sendo que cada estudo contribui com uma parte para o avanço da ciência. 
CONCLUSÕES 


\section{CONCLUSÕES}

A análise dos dados, de acordo com os critérios estabelecidos neste trabalho, possibilitou as seguintes conclusões:

7.1- existem diferenças significativas entre estruturas fundidas em titânio e cobalto-cromo. A menor interface encontrada foi nas estruturas fundidas em titânio (desajuste médio de $21,262 \mu \mathrm{m}$ ).

7.2- existem diferenças significativas entre estruturas fundidas em monobloco e após a soldagem a laser. Os melhores resultados foram encontrados nas estruturas após a soldagem a laser (desajuste médio de $19,943 \mu \mathrm{m})$.

7.3- não houve diferenças estatisticamente significativas entre os três cilindros das estruturas, fundidas em titânio e cobalto-cromo, antes e após soldagem a laser.

7.4- não houve interações entre as três condições estudadas (Material, Técnica e Cilindros). 
ANEXOS 
ANEXO 1- Descrição dos dados analisados

\begin{tabular}{|c|c|c|c|}
\hline \multicolumn{4}{|c|}{ Cilindro 1 } \\
\hline Amostra & Fundição & monoboco & após soldagem \\
\hline 1 & $\mathrm{Ti}$ & 21,665 & 22,915 \\
\hline 2 & $\mathrm{Ti}$ & 25,415 & 22,500 \\
\hline 3 & $\mathrm{Ti}$ & 20,830 & 10,000 \\
\hline 4 & $\mathrm{Ti}$ & 31,662 & 26,250 \\
\hline 5 & $\mathrm{Ti}$ & 25,412 & 13,750 \\
\hline 6 & $\mathrm{Co}-\mathrm{Cr}$ & 23,745 & 22,915 \\
\hline 7 & $\mathrm{Co}-\mathrm{Cr}$ & 42,915 & 31,665 \\
\hline 8 & $\mathrm{Co}-\mathrm{Cr}$ & 30,000 & 23,747 \\
\hline 9 & $\mathrm{Co}-\mathrm{Cr}$ & 25,415 & 16,250 \\
\hline 10 & Co-Cr & 27,082 & 29,580 \\
\hline
\end{tabular}

\begin{tabular}{|c|c|c|c|}
\hline \multicolumn{4}{|c|}{ Cilindro 2 } \\
\hline Amostra & Fundição & monoboco & após soldagem \\
\hline 1 & $\mathrm{Ti}$ & 23,745 & 16,665 \\
\hline 2 & $\mathrm{Ti}$ & 20,415 & 18,332 \\
\hline 3 & $\mathrm{Ti}$ & 19,580 & 15,415 \\
\hline 4 & $\mathrm{Ti}$ & 24,580 & 17,082 \\
\hline 5 & $\mathrm{Ti}$ & 25,832 & 27,500 \\
\hline 6 & $\mathrm{Co}-\mathrm{Cr}$ & 24,997 & 27,497 \\
\hline 7 & $\mathrm{Co}-\mathrm{Cr}$ & 22,497 & 22,080 \\
\hline 8 & $\mathrm{Co}-\mathrm{Cr}$ & 26,665 & 21,665 \\
\hline 9 & $\mathrm{Co}-\mathrm{Cr}$ & 27,497 & 12,500 \\
\hline 10 & Co-Cr & 32,082 & 21,662 \\
\hline
\end{tabular}




\begin{tabular}{|c|c|c|c|}
\hline \multicolumn{4}{|c|}{ Cilindro 3 } \\
\hline Amostra & Fundição & monoboco & após soldagem \\
\hline 1 & $\mathrm{Ti}$ & 16,665 & 13,750 \\
\hline 2 & $\mathrm{Ti}$ & 34,997 & 19,165 \\
\hline 3 & $\mathrm{Ti}$ & 26,245 & 19,582 \\
\hline 4 & $\mathrm{Ti}$ & 27,497 & 15,415 \\
\hline 5 & $\mathrm{Ti}$ & 21,247 & 13,750 \\
\hline 6 & $\mathrm{Co}-\mathrm{Cr}$ & 25,415 & 19,997 \\
\hline 7 & $\mathrm{Co}-\mathrm{Cr}$ & 29,577 & 14,997 \\
\hline 8 & $\mathrm{Co}-\mathrm{Cr}$ & 27,915 & 22,912 \\
\hline 9 & Co-Cr & 33,332 & 21,250 \\
\hline 10 & Co-Cr & 20,000 & 17,497 \\
\hline
\end{tabular}




\section{REFERÊNCIAS BIBLIOGRÁFICAS}




\section{REFERÊNCIAS BIBLIOGRÁFICAS}

1. ADELL, R.; LEKHOLM, B.; ROCKLER,B. BRÄNEMARK, P.I. A 15-year study of osseointegrated implants in the treatment of edentulous jaw. Int. J. oral Surg., v. 10, n. 6, p. 387-416, Dec. 1981.

2. APOTHEKER, H.; NISHIMURA, I.; SEERATTAN, C. Laser-welded vs soldered nonprecious alloy dental bridges: A comparative study. Lasers Surg. Med., v. 4, n. 2, p. 207-13, 1984.

3. BERG, E. et al. Mechanical properties of laser-welded cast and wrought titanium. J. prosth. Dent., v. 74, n. 3, p. 250-7, Sept. 1995.

4. BERGENDAL, B.; PALMQVIST, S. Laser-welded titanium frameworks for fixed prostheses supported by osseointegrated implants: a 2year multicenter study report. Int. J. oral Maxillofac. Implants, v. 10, n. 2, p. 199-206, Mar./Apr.1995.

5. BERGENDAL, B.; PALMQVIST, S. Laser-welded titanium frameworks for implant-supported fixed prostheses: a 5-year report. Int. J. oral Maxillofac. Implants, v. 14, n. 1, p. 69-71, Jan./Feb. 1999.

6. BESSING, C. Evaluation of the castability of four different alternative alloys by measuring the marginal sharpness. Acta Odnt. Scand., v. 44, n. 3, p. 165-72, June 1986.

7. CARLSSON, B.; CARLSSON, G.E. Prosthodontic complications in osseointegrated dental impalnt treatment. Int. J. oral Maxillofac. Implants, v. 9, n. 1, p. 90-4, Jan./Feb. 1994. 
8. CARR, A.B.; BRANTLEY, W.A. Titanium alloy cylinders in implant framework fabrication: a study of the cilinder-alloy interface. J. prosth. Dent., v. 69, n. 4, p. 391-7, Apr. 1993.

9. CARR, A.B.; BRUNSKI, J.B.; HURLEY, E. Effects of fabrication, finishing, and polishing procedures on preload in prostheses using conventional gold and plastic cylinders. Int. J. oral Maxillofac. Implants, v. 11, n. 5, p. 589-98, 1996.

10. CHAI, T.; CHOU, C.K. Mechanical properties of laser-welded cast titanium joints under different conditions. J. prosth. Dent, v. 79, n. 4, p. 477-83, Apr. 1998.

11. CHAO, Y.; ZARB, G.A.; JUDES, H. A study into the use of chromiumcobalt alloy for constructing the framework for osseointegrated. Clinical Materials, v. 3, p. 309-15, 1988.

12. CHOI, C.H. Wironium cobalt-chromium removable partial denture technique. Quintessence den. tecnology, p. 39-48, 1995.

13. COUNCIL ON DENTAL MATERIALS, INSTRUMENTS AND EQUIPAMENTS. Report on base metal alooys for crown and bridge applications: benefits and risks. J. Amer. dent. Ass. v. 111, n. 3, p. 479-83, Sept. 1985.

14. COUNCIL ON DENTAL MATERIALS, INSTRUMENTS AND EQUIPAMENTS. Dental Association Specification of dental casting alloy. J. Amer. dent. Ass. v. 118, n. 3, p. 379, Mar. 1989.

15. CRAIG, R.G. Restorative dental materials, 8 ed. St Louis. Mosby, 1989. p. 434-58. 
16. DELLINGES, M.A.; TEBROCK, O.C. A measurement of torque values obtained with hand-held drivers in a simulated clinical setting. J.Prosthodont., v. 2, n. 4, p. 212-4, Dec. 1993.

17. DOBBERSTEIN, H. et al. SchweiBen von kobalt-chrom-, nickel-chromand silber-palladium-legierungen mittles festkörperlaser. Zahn Mund Kwferheilkd, v. 78, n. 3, p. 259-61, 1990.

18. GetTleman, L. Noble alloys in dentistry. Curr. Opin. Dent., v. 1, n. 2 , p. 218-21, Apr. 1991.

19. GOHEEN, K.L.; et al. Torque generated by handheld screwdrivers and mechanical torquing devices for osseointegrated implants. Int. J. oral Maxillofac. Implants, v. 9, n. 2, p. 149-55, Mar. 1994.

20. GOLL, G.E. Production of accurately fitting full-arch implant frameworks: part I - clinical procedures. J. prosth. Dent., v. 66, n. 3, p. 377-84, Sept. 1991.

21. GORDON, T.E. SMITH, D.L. Laser welding of prosthesis - an initial report. J. prosth. Dent., v. 24, n. 4, p. 472-6, Oct. 1970.

22. GORDON, T.E. SMITH, D.L. Laser welding of ceramic fixed prostheses. Dent. Digest, p. 306-9, July 1970.

23. GULBRANSEN, H.J. How do you test a cast framework fit for a full-arch fixed implant-supported prosthesis. Int. J. Maxillofac Implants, v. 9, n. 4, p. 470-4, 1994.

24. GYLLENRAM,F. Handling and hardware. The two ultimate parameters for a clinically acceptable fit. Nobelpharma News, v. 8, n. 4, p. 4-5, 1994. 
25. HANEY, S.C.; MEIERS, J.C. In vitro study of intraoral welding procedures for pure titanium. Quintessence Int. v. 27, n. 12, p. 841-7, Dec. 1996.

26. HELLDÉN, L.B.; DÉRAND, T. Description and evaluation of a simplified method to achieve passive fit between cast titanium frameworks and implants. Int. J. oral Maxillofac Implants, v. 13, n. 2, p. 190-6, 1998.

27. HRUSKA, A.R. Intraoral welding of pure titanium. Quintessence Int., v. 18, n. 10, p. 683-8, Oct. 1987.

28. HULLING, J.S.; CLARK, R.E. Comparative distortion in three-unit fixed prostheses joined by laser welding, conventional soldering or casting in one piece. J. dent. Res. v. 56, n. 2, p. 128-34, Feb. 1977.

29. HULTERSTRÖM, M.; NILSSON, U. Cobalt-chromium as a framework material in implant-supported fixed prostheses: a preliminary report. Int. J. oral Maxillofac. Implants, v. 6, n. 4, p. 475-80, 1991.

30. HULTERSTRÖM, M.; NILSSON, U. Cobalt-chromium as a framework material in implant-supported fixed prostheses: a 3-year follow-up. Int. J. oral Maxillofac. Implants, v. 9, n. , p. 449-54, 1994.

31. INTERRUGUI, J.A. et al. Evaluation of three impression techniques for osseointegrated oral implants. J. prosth Dent., v. 69, n. 5, p. 503-9, May 1993.

32. ISA,Z.M.; HOBKIRK,J.A. The effects of superstructure fit and loading on individual implant units: Part I. The effects of tightening the gold screws and placement of superstructure with varying degrees of fit. Int. J. Prosthodontic Rest. Dent., v. 3, n. 6, p. 247-53, Dec. 1995. 
33. JAARDA,M.J.; RAZZOOG,M.E.; GRATTON,D.G. Ultimate tensile strength of five interchangeable prosthetic retaining screws. Implant Dent., v. 5, n. 1, p. 16-9, Spr. 1996.

34. JEMT, T. Failures and complications in 391 consecutively inserted fixed prostheses supported by Branemark implants in edentulous jaws: a study of treatment from the time of prosthesis placement to the first annual checkup. Int. J. oral Maxillofac. Implants, v. 6, n. 3, p. 2706, Fall 1991.

35. JEMT, T.; LINDÉN,B.; LEKHOLM,U. Failures and complications in 127 consecutively placed fixed partial prostheses supported by Branemark implants: from prosthetic treatment to first annual checkup. Int. J. Maxillofac. Implants, v. 7, n. 1, p. 40-4, Spr. 1992.

36. JEMT, T. How do you test a cast framework fit for a full-arch fixed implant-supported prosthesis. Int. J. oral Maxillofac. Implants, v. 9, n. 4, p. 470-4, 1994.

37. JEMT,T. Three-dimensional distortion of gold alloy castings and welded titanium frameworks. Measurements of the precision of fit between completed implant prostheses and master casts in routine edentulous situations. J. oral Rehabil., v. 22, n. 8, p. 557-64, Aug. 1995.

38. JEMT, T.; RUBENSTEIN,J.E.; CARLSSON, L.; LANG, B.R. Measuring fit and the implant prosthodontic interface. J. prosth Dent, v. 75, n. 3, p. 314-24, Mar. 1996.

39. JEMT, T. In vivo measurements of precision of fit involving implantsupported prostheses in the edentulous jaw. Int. J. oral Maxillofac. Implants, v. 11, n. 2, p. 151-7, Mar. 1996. 
40. JÖRNEUS, L.; JEMT, T.; CARLSSON, L. Loads and designs of screw joints for single crowns supported by osseointegrated implants. Int. J. oral Maxillofac. Implants, v. 7, n. 3, p. 353-9, Fall 1992.

41. KALLUS, T.; BESSING, C. Loose gold screws frequently occur in fullarch fixed prostheses supported by osseointegrated implants after 5 years. Int. J. oral Maxillofac. Implants, v. 9, n. 2, p. 169-78, Mar. 1994.

42. KAN J.K. et al. clinical methods for evaluating implant framework fit. J. prosth. Dent., v. 81, n. 1, p. 7-13, Jan. 1999.

43. KANO, S.C. Disajustment of prostheitic components using different alloys. J. dent. Res., v. 74, n. 3, p. 806, 1995. / Abstract n. 206 /

44. KANSU, G; AYDIN, A.K. Evaluation of the biocompatibility of various dental alloys: part I - toxic potentials. Europ. J. Prosthodont. Restorat. Dent., v. 4, n. 3, p. 129-36, Sept. 1996.

45. KARELLOS, N.D. et al. A simplified method for measuring photomicrographs. Implant Dent., v. 5, n. 1, p. 170-3, Fall 1996.

46. KAUFMAN, H.W. Clinical applications of lasers in dentistry. Comp.Continuing Educ. Dent., v. 9, n. 3, p. 548-53, Mar. 1988.

47. KLINEBERG, I.J.; MURRAY,G. M. Design of superstructures for osseointegrated fixtures. Swed. dent. J., v. 28, p. 63-9, 1985.

48. MARKLEY, M.R. The wax pattern. Dent. Clin.N.Am., p. 615-23, Nov. 1958. 
49. MAY, K.B. et al. The precision of fit at the implant prosthodontic interface. J. prosth. Dent., v. 77, n. 5, p. 497-502, May 1997.

50. McAlARNEY, M.E.; STAVROPOULOS, D.N. Determination of cantilever length-anterior-posterior spread ratio assuming failure criteria to be the compromise of the prosthesis retaining screwprosthesis joint. Int. J. oral Maxillofac. Implants, v. 11, n. 3, p. $331-9$, May 1996.

51. McCARTNEY, J. Intraoral connection of individual abutment attachments for an osseointegrated implant-supported prosthesis. J. prosth dent., v. 66, n. 6, p. 799-803, Dec. 1991.

52. McCARTNEY, J.W.; DOUD,R. Passive adaptation of the prosthesisimplant interface by soldering gold cylinders to the framework casting. J. prosth. Dent., v. 70, n. 1, p. 17-20, July 1993.

53. McCARTNEY, J.W.; PEARSON, R. Segmental framework matrix: master cast verification, corrected cast guide, and analog transfer template for implant-supported prostheses. J. prosth. Dent., v. 71, n. 2, p. 197-200, Feb. 1994.

54. McGLUMPHY, E.A.; MENDEL, D.A.; HOLLOWAY, J.A. Implant screw mechanics. Dent. Clin. N. Amer., v. 42, n. 1, p. 71-89, Jan. 1998.

55. MILLINGTON, N.D.; LEUNG,T. Stress on an implant superstructure in relation to its accuracy of fit. J. dent. Res., v. 71, p. 529, 1992. / Abstract n. $108 /$

56. NEO,T.K. et al. Mechanical properties of titanium connectors. Int. J. Prosthodont., v. 9, n. 4, p. 379-93, July/Aug. 1996. 
57. ÖRTORP,A.; LINDEN, B.; JEMT,T. Clinical experiences with laserwelded titanium frameworks supported by implants in the edentulous mandible: a 5-year follow-up study. Int. J. Prosthodont., v. 12, n. 1, p. 65-72, Jan. 1999

58. PAREL, S. How do you test a cast framework fit for a full-arch fixed implant-supported prosthesis. Int. J. oral Maxillofac. Implants, v. 9, n. 4, p. 470-4, 1994.

59. PARR, G. R.; GARDNER, L.K.; TOTH, R.W. Titanium: The mystery metal of impalnt dentistry. Dental materials aspects. J. prosth. Dent., v. 54, n. 3, p. 410-4, Sept. 1985.

60. PAVLATOS,J. Mandibular implant-supported overdentures. Implants CDS Reviews, Mar. 1997.

61. RANGERT,B.; JEMT, T.; JORNEUS, L. Forces and moments on Brånemark implants. Int. J. oral Maxillofac. Implants, v. 4, n. 3, p. 241-7, Fall 1989.

62. RIEDY, S.J.; LANG, B.R.; LANG, B.E. Fit of implant frameworks fabricated by different techniques. J. prosth. Dent., v. 78, n. 6, p. 596-604, Dec. 1997.

63. ROGGENSACK, M.; WALTER,M.H.; BÖNING,K.W. Studies on laserand plasma-welded titanium. Dent Mater, v. 9, p. 104-7, Mar. 1993.

64. RUBENSTEIN, J.E. Stereo laser-welded titanium impalnt frameworks: Clinical and laboratory procedures with a summary of 1-year clinical trials. J. prosth Dent. v. 74, n. 3, p. 284-93, Sept. 1995. 
65. SAKAGUCHI, R.L.; BORGERSEN, S.E. Nonlinear contact analysis of preload in dental implant screws. Int. J. oral Maxillofac. Implants, v. 10, n. 3, p. 295-302, May 1995.

66. SARTORI, I.A.M. Análise comprativa da interface intermediário estético/cilindro protético, torneados em ouro ou em plástico antes e após as fundições. Ribeirão Preto, 1999. 122p. Dissertação (Mestrado) - Faculdade de Odontologia de Ribeirão Preto, Universidade de São Paulo.

67. SCHIEFFLEGER, B. E.; et al. Comparision of accuracy of multiunit onepiece castings. J. prosth Dent., v. 54, n. 6, p. 770-6, Dec. 1985.

68. SJÖGREN, G; ANDERSSON, M.; BERGMAN, M. Laser welding of titanium in dentistry. Acta odont. scand., v. 46, n. 4, p. 247-53, Aug. 1988.

69. SKALAK, R. Biomechanical considerations in osseointegrated prostheses. J. prosth. Dent., v. 49, n. 6, p. 843-8, June 1983.

70. SORENSEN, J.A.; AVERA, S.P.; TOMAS, C. Comparison of interface fidelity of impalnt systems. J. dent. Res., v. 70, n. 3, p. 540, Mar. 1991. / Abstract n. 2191 /

71. STENBERG, T. Release of cobalt from cobalt chromium alloy constructions in the oral cavity of man. Scand. J. Dent. Res., v. 90, n. 6, p. 472-9, Dec. 1982.

72. SUTHERLAND, J.K.; HALLAM, R.F. Soldering technique for osseointegrated implant prostheses. J. prosth. Dent., v. 63, n. 2, p. 242-4, Feb. 1990. 
73. TAN, K. et al. Three dimensional analysis of the casting accuracy of one-piece, osseointegrated implant-retained prostheses. Int. J. Prosthodontics., v. 6, n. 4, p. 346-63, July/ Aug. 1993.

74. TAYLOR, D.F.; LEIBFRITZ, W.A.; ADLER, A.G. Physical properties of chromium-cobalt dental alloys. J. Amer. Dent. Ass., v. 56, n. 3, p. 343-51, Mar. 1958.

75. THOUPOS, G.A. et al. Connecting implant framework segments. Implant Dent., v. 4, n. 2, p.97-9, Sum. 1995.

76. WANG,R.R.; CHANG, C.T. Thermal modeling of laser welding for titanium dental restorations. J. prosth. Dent., v. 79, n. 3, p. 335-42, Mar. 1998.

77. WANG,R.R.; WELSCH, G.E. Joining titanium materials with tungsten inert gas welding, laser welding, and infrared brazing. J. prosth. Dent., v. 74, n. 5, p. 521-30, Nov. 1995

78. WASKEWICZ, G.A.; OSTROWSKI, J.S.; PARKS, V.J. Photoelastic analysis of stress distribuition transmitted from a fixed prothesis attached of osseointegrated implants. Int. J. oral Maxillofac. Implants, v. 9, n. 4, p. 405-11, 1994.

79. WEE, A.G.; AQUILINO, S.A.; SCHNEIDER, R.L. Strategies to achieve fit in implant prosthodontics: a review of the literature. Int. J. Prosthodontics., v. 12, n. 2, p. 167-78, Mar./Apr. 1999.

80. YAMAGISHI, T.; ITO, M.; FUGIMURA, Y. Mechanical properties of laser welds of titanium in dentstry by pulsed Nd:YAG laser apparatus. J. prosth. Dent., v. 70, n. 3, p. 264-73, Sept. 1993. 
81. ZARB, G.A.; SCHMITT, A. The longitudinal clinical effectiveness of osseointegrated dental implants: the Toronto study. Part III: problems and complications encountered. J. prosth Dent., v. 64, n. 2, Aug. 1990.

82. ZOIDIS, P.C.; WINKLER, S.; KARELLOS, N.D. The effect of soldering, electrowelding, and cast-to procedures on the accuracy of fit of cast implant bars. Implant Dent., v. 5, n. 3, p. 163-8, Fall 1996. 
ABSTRACT 


\section{ABSTRACT}

The passivity of adaptation for prostheses supported by osseointegrated implants is basic requirement for the long-term sucess of the treatment.

The purpose of this study was to evaluate the adaptation of the abutment to titanium or cobalt-chromium one-piece castings before and after laser welding.

A total of 30 cylinders machined plastic and 15 cylinders bars were inserted to joint the prosthetics componentes. Each specimen, had three prosthetics components joined. A total of 10 specimens wewr obtained 5 casted with titanium and 5 with cobalt-chromium alloy.

The measurements of interfaces were made after and before laser welding with a comparative microscope. The results showed the greatest interface $(26,164 \mu \mathrm{m})$ of the one-piece castings compared to the laser welding specimens $(19,943 \mu \mathrm{m})$. Titanium castings showed best results statistically significant when compared to the cobalt-chromium specimens. 